\title{
Cytotoxic effects of Gamma Irradiation on
} Aspergillus occultus MN259598 strain to augment biological copper nanoparticle synthesis and to corroborate antibacterial properties on food- borne pathogens

Rathijit Mallick

Pondicherry University

Regina Sharmila Dass ( $\nabla$ reginadass@gmail.com )

Pondicherry University

Pranab Kumar Mahata

Pondicherry University

Mayukhmita Ghose

Pondicherry University

\section{Research Article}

Keywords: Aspergillus occultus, Copper nanoparticles, Biological synthesis, Gamma irradiation, Myconanotechnology

Posted Date: March 22nd, 2022

DOI: https://doi.org/10.21203/rs.3.rs-1375861/v2

License: (c) (1) This work is licensed under a Creative Commons Attribution 4.0 International License. Read Full License 


\section{Abstract}

The current scientific study focuses on the effects of gamma irradiation on fungal isolate Aspergillus occultus MN259598 strain to monitor the efficacy of extracellular Copper nanoparticle (CuNP) synthesis using Copper acetate as the starting material through a biological route. This study is a first report of Gamma irradiation being employed in order to document the possible role of irradiational stress in nanoparticles synthesis in Aspergillus occultus MN259598. Gamma irradiation doses of $0.66 \mathrm{~Gy}, 0.99 \mathrm{~Gy}$, $1.33 \mathrm{~Gy}, 1.66 \mathrm{~Gy}$ and $1.99 \mathrm{~Gy}$ were used for the induction of physiological changes. Macromorphological alterations of the mycelia were observed when grown in broth medium. The lethalities and fungal architectural distortions observed as a part of the study profile of micromorphological characteristics of the irradiated organism were documented. The irradiated fungal cell free extracts (CFE) were used for the production of biogenic CuNPs through optimization studies. Simultaneously, the CFE of the wild type strain was also used for the NP synthesis. The particles were characterized employing UV-Visible (UV-Vis) spectrophotometry, Dynamic Light Scattering (DLS), Fourier Transform InfraRed spectroscopy (FTIR), Scanning Electron Microscopy (SEM) and X-Ray Diffraction (XRD) analyses. Sizes of the NPs of treated $(66.3 \mathrm{~nm})$ and wild type strain (300 nm approx.) were found to differ enormously. The antimicrobial activity of CuNPs was determined using different food-borne pathogenic bacteria namely Escherichia coli, Bacillus cereus and Listeria monocytogenes.

\section{Introduction}

The revolution in the field of nanotechnology has opened many doorways in the world, medical science being the most significant one. Copper, since ancient times, has been used in households for its broadspectrum antimicrobial activities against an array of human pathogens. With the advent of modern technology, it is now being employed in its nano form to engineer biosensors (for e.g., Glucose detector) due to a heightened catalytic activity. This application has served to be a reliable diagnostic measure for diabetics (Type II) who need constant monitoring of blood glucose level [1, 2]. They are used in cable wires due to their highly thermal and electrically conductive properties which make them a great choice of metal to be used. As compelling as it is, the biological aspect of Copper cannot possibly be avoided. In biological systems, Copper is an extremely important component of several enzymes, namely, Copper transporting adenosine triphosphates [3, 4], cupro proteins, which play significant roles as cofactors in enzymes such as tyrosine kinases, cytochrome-c oxidase, superoxide dismutase etc. They help aid in enzymatic activities and act as a trace metal in cell energy production through mitochondrial respiration $[5,6]$. They also take part in metabolism of cell walls in plants. Copper plays an admirable role in biological systems as antioxidants by scavenging free radicals generated in cells to protect DNA and other macromolecules from being destroyed [7-9]. Copper shows high antibacterial activity against certain human pathogens [10], especially gram-negative bacteria. Surfaces of copper nanoparticles, just like any other nanoparticles, are highly charged due to their small size and show a high resonating property called Surface Plasmonic Resonance (SPR). Such phenomenon facilitates their interaction with the bacterial membranes and eventually kills them by cell lysis. The exact mechanism of how these 
nanostructures achieve this level of specificity is yet unknown to researchers but it seems that the released $\mathrm{Cu}^{2+}$ ions disrupt and penetrate the bacterial cell membranes. This causes an intervention of the many cellular biochemical pathways by inactivating enzymes and causing DNA damage [11-13]. Nanoparticles have drawn considerable worldwide attention due to their promising and unusual properties, namely- chemical, photoelectrochemical, optical [13], etc., to mention a few. As researchers have dug deep into the subject, some extravagant features like, enhanced structural integrity have come to light, which make them suitable to be used in an assemblage of applications such as- medicine (antimicrobial properties against an array of bacterial and fungal pathogens, target specific delivery of drugs and drug-nanoparticle conjugates, nanorobotics as a cutting edge tool for early diagnosis of diseases, microsurgery at tissue or genetic level), magnetic, catalysis, photo-electrochemical, electronics, optics [14], mechanics etc.[15, 16]. To achieve the nano range, a series of protocols have been used by the scientists. Most of these methods employ toxic chemicals which are otherwise hazardous for the environment as well as for human health. The other major drawbacks exhibited by the chemical synthesis are- intensified capital, high temperature required to carry out the experiments and objectionable features like by-products of the reactions released into nature as waste material and many more $[17,18]$. Ever since chemical methods for nanoparticle synthesis have caused great toxicity to the environment, scientists have inquired to find alternatives that can substitute the production $[18,19]$. As a solution to this problem, they have come up with an exciting mechanism which forms a bridge of interaction between the inorganic metal salts and bio-specimens like- bacteria, fungi and plants, leading to the mode of 'green synthesis' [20-22]. Biological entities like plants, fungi, actinomycetes and bacteria have successfully been used in the biosynthesis of these nanostructures. Biosynthesis using the aforementioned organisms has driven researchers to come up with simple, inexpensive, easy and viable alternatives to the more complex physical and chemical counterparts. The potential of these organisms to synthesize numerous kinds of nanomaterials [23] can be put into use for exploring new materials. The rationales behind using green methods for nanoparticle synthesis are that the resultant products are ecofriendly, non-toxic to the environment, easy downstream processing, cost effective nature and reliable, leading to an enhanced reduction in the usage of toxic chemicals [24].

Ionization by irradiation is a powerful yet weak form of energy that when comes in contact with atoms or molecules, causes them to ionize or excite to a higher energy state where uncharged molecules are produced like singlet oxygen moiety $(\mathrm{O} \cdot)$, singlet hydrogen moiety $(\mathrm{H} \cdot)$, hydroxide radicals $(\mathrm{OH} \cdot)$, peroxides from radiolysis of water present in and around the cells [25]. Water $\left(\mathrm{H}_{2} \mathrm{O}\right)$ is usually present in and around the macromolecules like DNA, proteins etc., as a hydration layer. When these water molecules are broken down into their free radical form, the $\mathrm{OH}$. radicals generated can alone cause $90 \%$ damage to the genetic material. This is an indirect mode of damage compared to a direct one where the high energy photons (of Q-rays) released from the atomic nuclei are directly deposited on the DNA [26]. As a consequence, two different types of DNA damage can occur: single strand and double strand breakages. These unusual appearances in the hereditary material sends signal to the cell to repair the damage. In case of single strand DNA break, as one of the complementary strands is un-affected, the damaged/ mutated portion of one strand is excised by the repair system and is again restored using the complementary strand as the 
template. So, the structural uniformity of one strand is very important in single strand damage. Cells that are devoid of this repair system, are more prone to radiosensitivity [27, 28]. Double strand breaks are repaired through either homologous recombination or non-homologous end joining to avoid perilous after effects that can otherwise cause cell death [29]. A team of researchers showed in their study as to how these ionizing radiations can cause architectural and physiological alterations in fungal hyphae [30], a field that has been inadequately researched thus far. They further have shown how the effect of Gamma irradiation and other ionizing radiations lowered the rate of spore germination as a certain dose level was used. Although, metal tolerance in fungal species like Aspergillus has previously been documented with Cadmium (Cd), scientific reports on nanoparticle synthesis from bulk metal precursors by fungal species, subjected to irradiation is completely unavailable. Here, we present the use of Aspergillus occultus MN259598 in the production of CuNPs through a biological route, and the effect that gamma irradiation has on its synthesis potential, for the very first time.

\section{Materials And Methods}

\subsection{Fungal isolate}

The fungal isolate was a result of the isolation techniques involving soil samples that had been previously collected as a part of an ongoing research at the Fungal Genetics and Mycotoxicology Laboratory. The soil samples had been collected from the region of Madhya Pradesh, Central India, for studying the fungal flora associated with those soils. The fungal isolates were obtained and cultured in pure form by following standard protocols in order to study both macro-morphological and micromorphological characteristics. Aspergillus occultus was revealed to be one of the soil samples' fungal inhabitants upon isolation. The same was identified up to the genus and species level using fungal keys and manuals [31-34] and authenticated using DNA-based Fungal barcoding.

\subsection{Glycerol stock preparation}

A storage vial ( $10 \mathrm{ml}$ capacity) containing $5 \mathrm{ml}$ of $50 \%$ glycerol stock was used for preserving the culture. The glycerol stock was prepared using appropriate amount of distilled water and glycerol $\left(\mathrm{C}_{3} \mathrm{H}_{8} \mathrm{O}_{3}\right)$. The mixture was sterilized by autoclaving at $121^{\circ} \mathrm{C}$ for $15 \mathrm{mins}$ and at a pressure of $15 \mathrm{lbs} / \mathrm{inch}^{2}$. A five-day old culture of the fungal isolate A. occultus MN259598 previously grown in potato dextrose broth (PDB) (HiMedia ${ }^{\circledR}$ ) and incubated at ambient laboratory conditions, was gently vortexed for 3-4 times. $1 \mathrm{ml}$ of the spore suspension was transferred to the glycerol stock storage container. Later, the vial was gently shaken for proper mixing of the spore suspension and was preserved at $4^{\circ} \mathrm{C}$ for further studies.

\subsection{Culture preservation}

Culture plates (Borosil S-Line ${ }^{\circledR}$ ) were used to prepare Mycological (Fungal) agar medium (Soya peptone$10 \mathrm{gms} /$ litre, Dextrose- $10 \mathrm{gms} /$ litre, Agar- $15 \mathrm{gms}$ / litre; Himedia $\left.{ }^{\circledR}\right)$. The petriplates were inoculated with A. occultus MN259598 using point inoculation technique. Also, culture tubes (Borosil@) containing fungal agar were prepared, inoculated and incubated at $28^{\circ} \mathrm{C}$ for five days. After the 5 th day, the 
petriplates and the culture tubes were sealed with parafilm ${ }^{\circledR}$ and were preserved in the refrigerator at $4^{\circ} \mathrm{C}$ in sterile storage pouches.

\subsection{Culture revival of $A$. occultus MN259598}

As and when the necessity for a fungal isolate for experimental methods arose, they were recovered from glycerol stocks by inoculating them onto Mycological agar plates. The cultures were inoculated by standard procedures and incubated at $28^{\circ} \mathrm{C}$.

\subsection{Phenotypic (morphological) characterization of $A$. occultus MN259598}

In order to study the phenotypic characteristics of the fungal test isolate, namely, A. occultus MN259598, different mycological media were used for studying the growth characteristics, like, Potato Dextrose Agar (PDA), Dichloran Rose Bengal Chloramphenicol Agar (DRBC) and Czapek Dox Agar (CDA) media. An antibacterial antibiotic, namely, Chloramphenicol (Sigma Aldrich) was added at the rate of $20 \mathrm{mg} / 1000$ $\mathrm{ml}$ in PDA and CDA. All media were prepared as per manufacturer's instructions, poured and were allowed to solidify. The test isolate was inoculated by point inoculation method and was incubated at $25^{\circ} \mathrm{C}$ for 3 to 11 days. Pictographs were taken at regular intervals to study growth patterns (Data not shown). Stereo-

binocular and light microscopic studies were performed. Macro-morphological characters were studied by naked eye observation. Alongside, Stereo-binocular microscopic (Magnus MSZ-Bi, Model: 13M1009) studies were carried out predominantly by achieving magnifications up to 20X. The micro-morphological characters were studied by preparing Lactophenol Cotton Blue (LPCB) wet mounts and light microscopic (Olympus $\mathrm{CH} 20 \mathrm{i}$ ) observations. The identity of the fungal isolate was established up to the genus level by microscopic observations using fungal keys and manuals.

\subsection{Genotypic characterization of $A$. occultus MN259598}

\section{Extraction of fungal genomic DNA}

In order to obtain high quality fungal DNA of $A$. occultus MN259598, a rapid purification kit for genomic DNA isolation was used (GeneJET ${ }^{\mathrm{T}}$, Thermo Fisher Scientific). As per manufacturer's instructions, at first, freshly grown mycelial mat of the fungus, preferably a four-day old culture was taken in mortar and pestle and was thoroughly ground using liquid nitrogen. Adequate grinding was performed to achieve mechanical shearing of the fungal mycelia. After that, $100 \mathrm{mg}$ of crushed mycelia was transferred to a $1.5 \mathrm{ml}$ microfuge tube along with $350 \mathrm{~mL}$ of Lysis Buffer A. The solution was vortexed for 10-20 mins for proper mixing. Then, $50 \mu \mathrm{L}$ of Lysis Buffer B was added to ensure breakage of resistant mycelium. Additionally, $20 \mu \mathrm{L}$ of RNase was added to the vial to deactivate any RNA released during the solution's preparation. After 10 mins of incubation at $65^{\circ} \mathrm{C}, 130 \mu \mathrm{L}$ of precipitation solution was added and the tube was gently inverted 2-3 times for thorough mixing. This was followed by a brief incubation for 5 mins on ice. Next, centrifugation was carried out for 5 mins at 14,000 rpm. About $400 \mu \mathrm{L}$ of supernatant was collected and was transferred to a fresh microfuge tube along with sequential addition of genomic DNA binding solution and ethanol (400 $\mu \mathrm{L}$ each). Eventually, $700 \mu \mathrm{L}$ of the prepared mixture was 
transferred to the spin column (provided with the kit) and the column was centrifuged at 8,000 rpm for 1 min. Following the removal of the flow-through solution, the left mixture was centrifuged for one minute using the same column. Thereafter, $500 \mu \mathrm{L}$ of Wash Buffer I was added to the column and was centrifuged at $10,000 \mathrm{rpm}$ for $1 \mathrm{~min}$. This was followed by centrifugation of the column at $14,000 \mathrm{rpm}$ for 3 mins with $500 \mu \mathrm{L}$ of Wash Buffer II, after discarding the flow-through of the previous step. Finally, a high yield of pure fungal genomic DNA (50 $\mu \mathrm{L}$ approx.) was achieved using two elution steps. In the 1 st step, $30 \mu \mathrm{L}$ of Elution Buffer was added to the centre of the column, incubated for $5 \mathrm{~min}$ at room temperature and then centrifuged at 10,000 rpm for $1 \mathrm{~min}$. In the 2 nd step, $20 \mu \mathrm{L}$ of Elution Buffer was added and the solution was collected in a new tube. The pure fungal DNA, thus obtained, was then used for PCR amplification.

\section{PCR amplification of the ITS region and the Beta-tubulin gene}

Once the DNA extraction procedure was completed, the sample was subjected to a standard quantification process $\left(\mathrm{ng} / \mathrm{\mu l}\right.$ ) using NanoDrop Spectrophotometer (Thermo Scientific $2000 \mathrm{c}^{\mathrm{TM}}$ ). The concentration and purity of DNA were checked and were used in PCR reactions. The reaction mixtures for the amplification of the ITS and the $\beta$-tubulin gene sequences were prepared using a commercial Kit namely Taq DNA polymerase 2x Master Mix RED, AMPLIQON [Tris-HCl, pH 8.5, (NH) ${ }_{2} \mathrm{SO}_{4}, 3 \mathrm{mM} \mathrm{MgCl}$, $0.2 \%$ Tween 20, $0.4 \mathrm{mM}$ of each dNTP mix (dATP, dCTP, dGTP, dTTP), Ampliqon Taq DNA polymerase, inert red dye and stabilizer]. The PCR reactions were carried out in a $25 \mu \mathrm{L}$ volume containing $12.5 \mu \mathrm{L}$ (Taq DNA Polymerase 2x Master Mix RED, Ampliqon PCR Enzymes And Reagents), Forward primer (10 pmoL) $2.0 \mu \mathrm{L}$, Reverse primer (10 pmoL) $2.0 \mu \mathrm{L}$, Template DNA $2.0 \mu \mathrm{L}$, Molecular biology grade water (HiMedia ${ }^{\circledR}$ ) $6.5 \mu \mathrm{L}$ for ITS gene and $12.5 \mu \mathrm{L}$ (Taq DNA Polymerase 2x Master Mix RED, Ampliqon PCR Enzymes and Reagents), Forward primer $(10 \mu \mathrm{M}) 1.0 \mu \mathrm{L}$; Reverse primer $(10 \mu \mathrm{M}) 1.0 \mu \mathrm{L}$; Template DNA $2.0 \mu \mathrm{L}$, Molecular biology grade water (HiMedia ${ }^{\circledR}$ ) $8.5 \mu \mathrm{L}$ for $\otimes$-tubulin gene amplification. The $200 \mu \mathrm{L}$ capacity PCR tubes were then placed in the PCR machine (Eppendorf Hamburg Mastercycler, Model: AG 22331). The cycling protocol consisted of an initial denaturation step of $94^{\circ} \mathrm{C}$ for $1 \mathrm{~min} 30 \mathrm{~s}, 32$ cycles of denaturation at $95^{\circ} \mathrm{C}$ for $35 \mathrm{~s}$, annealing for $55 \mathrm{~s}$ at $55^{\circ} \mathrm{C}$ for ITS and an initial denaturation step of $95^{\circ} \mathrm{C}$

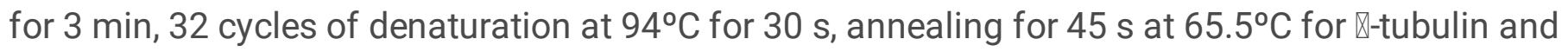
extension at $72^{\circ} \mathrm{C}$ for $1 \mathrm{~min}$ followed by a final extension of $10 \mathrm{~min}$ for ITS and $13 \mathrm{~min}$ for $\mathrm{X}$-tubulin at $72^{\circ} \mathrm{C}$. The PCR results were analyzed and documented using 1.5 percent agarose gel electrophoresis.

\section{Primer sequences}

The primer sequences of both ITS and $\beta$-tubulin sequences are as follows: ITS sequences (Synergy Scientific Services, Chennai, India)- ITS 1 (5'- TCCGTAGGTGAACCTGCGG-3'), ITS 4 (5'TCCTCCGCTTATTGATATGC-3') and $\beta$-tubulin gene (GENEi, Bangalore, India)- bT2a (5'GGTAACCAAATCGGTGCTGCTTT-3'), bT2b (5' - ACCCTCAGTGTAGTGACCCTTGG-3').

Sanger's sequencing of the ITS and $\beta$-tubulin sequences, Phylogenetic analysis and GenBank Submission 
The PCR-amplified products of the ITS and $\beta$-tubulin genes were sent to Applied Biosystems (Biokart India Pvt. Ltd., Bangalore, India) for Sanger sequencing. The ITS gene sequences were used to characterize the fungal isolate and GenBank Accession No. MN259598 was obtained.

\subsection{Scanning Electron Microscopy}

Scanning electron microscopic studies were also conducted in order to obtain the three-dimensional structures of the fungal isolate (A. occultus MN259598). In the current study, four-day old cultures contained erect conidiophores on the cultivation medium used. A drop of double-distilled water was placed on micro-coverslips. Conidiophores were then separated from the agar surface using microtweezers and were laid on the coverslips. The coverslips were allowed to dry briefly, coated with carbon (Hitachi, Model: E-1010) over a duration of 20 mins and were subjected to analysis.

\subsection{Irradiation studies}

Petri plates were prepared in order to inoculate the test organism onto sterile solidified Fungal agar medium. Sterility was maintained during the execution of every single step of the experimental procedure. Five-day old cultures were subjected to irradiation using gamma irradiation chamber (BRIT, Model: GC5000). Once the cultures were irradiated (with a dose rate of $1 \mathrm{kGy}, 1.5 \mathrm{kGy}, 2.0 \mathrm{kGy}, 2.5 \mathrm{kGy}, 3.0 \mathrm{kGy} / \mathrm{hour}$ respectively) for 40 mins, the culture plates were dismounted from the sample holder of the chamber and carefully shifted to the laboratory in sterile dark containers exclusively prepared for this purpose. Care was taken to incubate the irradiated cultures away from the exposition to light. The irradiation doses were given 4 days repeatedly. The rationale behind this approach was to shorten the time period for the organism to recover from the stressed condition followed by the isolate's ability to continue synthesis of nanoparticles in the desired nano size-range. Morphological and fungal architectural distortions were studied. The irradiated isolates were then subjected to nanoparticle synthesis on the 5 th day. Appropriate controls were maintained.

\subsection{Biogenic copper nanoparticle synthesis}

In order to achieve Copper nanoparticle synthesis by biological methods, Copper acetate monohydrate $\left[\mathrm{Cu}\left(\mathrm{CH}_{3} \mathrm{COO}\right)_{2}\right.$ ] and Sodium hydroxide $(\mathrm{NaOH})$ extraction protocol was followed, wherein, a series of molar concentrations of the metal precursor solution was used with $0.06 \mathrm{M}$ of sodium hydroxide initially. However, modifications were made to obtain optimum synthesis noticeable in terms of the efficiency of synthesis by visual observation (colour change from straw yellow to brick red and/ or muddy brown) [35].

\subsubsection{Protocol optimization for synthesis of biogenic Copper oxide nanoparticle}

A series of protocols were followed in order to control the size of the biogenic CuONPs, and to standardize the procedure. Extraction of the nanoparticles from media (PDB) alone was carried out, using both $0.01 \mathrm{M}$ and $0.001 \mathrm{M}$ metal precursor solutions of Copper acetate monohydrate of analytical grade. Sodium hydroxide $(0.6 \% \mathrm{NaOH}$; Himedia, Molecular biology grade) was used as a reducing agent to 
improve the rate of reaction. For the synthesis of nanoparticles from the wild type isolate and irradiated fungal isolates, the cell free extract (CFE) was separated from the mycelial mat by using Whatman filter paper No. 1. The pH of CFE, metal salt solution and $\mathrm{NaOH}$ were checked using digital $\mathrm{pH}$ meter. Then, with the addition of a magnetic bead, the conical flasks were placed on the magnetic stirrer (REMI $1 \mathrm{MLH}$ ) at a speed of $370 \mathrm{rpm}$. An aliquot of Copper acetate solution $(20 \mathrm{ml})$ was added to it under vigorous stirring condition while the $\mathrm{pH}$ was also being monitored. After stirring for about $2-3 \mathrm{mins}, 20 \mathrm{ml}$ of $0.6 \mathrm{M}$ $\mathrm{NaOH}$ solution was added drop-wise and the $\mathrm{pH}$ was checked again. Following this, the solution was stirred for 10 mins. Colour changes that were observed throughout the process, were being documented by taking pictographs. After the completion of stirring, the flask was placed in water bath that was previously maintained between $78-80^{\circ} \mathrm{C}$ for 20 mins. As the colour changes became noticeable into dark red, blackish red or muddy brown, the flasks were drawn out of the water bath. The colour changes were indicative of the reduction of Copper, as stated in previous studies [35, 36]. An additional stirring was followed for 10 mins to complete the reaction. The flask was then left undisturbed to cool down to room temperature. They were later subjected to extraction of the nanoparticles. In the extraction process, aliquots of the solution were poured into respective sterile tubes $(50 \mathrm{ml})$ and were centrifuged at 8,600 rpm for 20 mins. After the first spin, the supernatant was discarded and the pellet was washed with $70 \%$ ethanol, followed by a $100 \%$ ethanol wash at the same speed to dissolve the impurities in the solution from the pellet. Next, acetone was used 2-3 times, additionally and the tubes were spun under same conditions, to get a less crude/ unadulterated final product in terms of pure nanoparticle form. Later, the falcon tubes were covered adequately with tissue paper and kept for drying overnight. Following the drying step, the residual particles were retrieved from the tubes the next day with the help of a sterile spatula. The contents were transferred into a mortar, and ground into a fine powder texture which was stored in microcentrifuge tubes for further characterizations.

\section{Characterization Of Copper/ Copper Oxide (Cu/ Cuo) Nanoparticles}

The working solutions of the NP suspension comprised aliquots of $1.5 \mathrm{ml}$ each, dispensed in $2 \mathrm{ml}$ microfuge tubes. The tubes were then subjected to sonication for 20 mins using an appropriate dispersant, namely, Poly Ethylene Glycol (PEG). The absorbance was recorded in the wavelength range of 200-800 nm (Shimadzu, Model- UV 3600 Plus). Nanoparticle suspensions (4 ml) from wild type and irradiated isolates were aliquoted, out of which $1.2 \mathrm{ml}$ of the samples each were used to determine the particle size and density. The samples were prepared by using Polyethylene Glycol (20\% PEG) and were sonicated for 20 mins for uniform particle distribution throughout. The technique was carried out using the particle size analyzer (Malvern Zetasizer, Model: ZEN1600). The 3-dimensional structure of nanoparticles were studied using scanning electron microscopy. The nanoparticles were dusted onto the sample holder and placed inside the coating equipment (Hitachi, Model: S-3400N).). They were sputter coated with Carbon (Hitachi, Model: E-1010) over a duration of 20 mins and then examined. The composition of the nanoparticles was studied using Fourier transformed infra-red spectroscopy (FTIR) (Nicolet, Thermo scientific, Model: 6700) and X-ray diffraction (XRD) analysis (PANalytical X'Pert ProTM). 


\section{Antimicrobial Assays Using Biogenic Nanoparticles 4.1 Antibacterial effects of CuNPs from wild type strain using Well diffusion assay}

Mueller-Hinton (HiMedia ${ }^{\circledR}$ ) Agar plates were prepared by using the required medium contents. The plates were marked accordingly and were inoculated with subsequent bacterial cultures (Bacillus cereus, Escherichia coli and Listeria monocytogenes) by spread plate technique using appropriate lab accessories. Later, with the help of a sterile stainless steel cork borer, the agar surface was bored and wells were created, to place the nanoparticle suspensions. Then, $100 \mu \mathrm{l}$ of different nanoparticle concentrations $(20 \mu \mathrm{g} / \mathrm{mL}, 40 \mu \mathrm{g} / \mathrm{mL}, 60 \mu \mathrm{g} / \mathrm{mL}, 80 \mu \mathrm{g} / \mathrm{mL})$ were added into four different wells while Kanamycin $(100 \mu \mathrm{g} / \mathrm{mL})$ was used as a positive control. The fifth well contained sterile distilled water and served as negative control.

\section{Results And Discussions}

\subsection{Morphological and Genetic characterization of A. occultus (Wild-Type and Irradiated isolates) by Microscopy and DNA Barcoding}

An examination of the cultural characteristics of the test isolate A. occultus MN259598 was carried out alongside the main objective of this paper (complete data not shown here) to document and observe growth patterns of the organism, employing various mycological media. Aspergillus occultus MN259598 was grown on different media, namely- Czapek-Dox agar (CDA), Dichloran Rose Bengal Chloramphenicol (DRBC) agar, synthetic and semi-synthetic Potato Dextrose agar (PDA) and Fungal agar media. $A$. occultus exerted minor macro-morphological changes over a duration of six days of incubation. Many researchers in their work previously [34] have documented as to how nutrient availability and other extrinsic parameters could influence the fungal growth patterns as shown in (Fig. 1). As the organism grew into mature, interwoven hyphal filaments, sclerotia began to develop with age, which are known to reserve food material for utilization under uncongenial conditions and were detectable in PDA and Fungal agar media. Also, sclerotia formation, which generally are considered as a prerequisite to sexual development [32] were seen in all the cultures irradiated with different doses of Gamma irradiation (1 kGy, $1.5 \mathrm{kGy}, 2.0 \mathrm{kGy}, 2.5 \mathrm{kGy}, 3.0 \mathrm{kGy} / \mathrm{hr}$ each)

The colonies ranged from $0.25-1 \mathrm{~cm}$ in diameter in a highly crowded plate. Otherwise, the growth was profuse and spread as concentric waves when colonies fused with each other. The species started to appear as hyaline with conidial heads being white in the initial stages, transforming to a velvety outline of actively growing hyphae. The hyphae eventually changed through the color shades of cream, cream buff to light brownish, biscuit- brown, powdery colony upon maturation. Conidial heads were conspicuously circular when viewed with the naked eye and under the stereo-binocular microscope. They gradually spread layer by layer producing young conidiophores in concentric rings which were easily differentiable. Sometimes in old cultures they showed a coloration of snuff-brown. When viewed under stereo-binocular 
microscope, a well distributed colony of conidiophores (Fig. 2) was spotted. When higher magnifications were used (20X), young conidiophores bearing the globose conidial heads were perceived. Long conidiophores (Fig. 3) were observed with a maximum of one to two septa. These exceptionally long conidiophores and cultural features are characteristic of yet another species namely Aspergillus wentii. In spite of meticulous inspections of the micromorphological characters, it led to an initial ambiguity in species identification and was overcome by using DNA barcoding of the Internal Transcribed Spacer (ITS) and $\beta$-tubulin gene sequences. Conidiophores were thick-walled, smooth, enlarged at tips to form vesicles varying in diameter; and were yellow to fade brown. Biseriate sterigma were observed circumferentially on the globose vesicle which in turn bore chains of conidia in basipetal succession. Spores were found to be brown, but sometimes young conidia took up the Lactophenol cotton blue (LPCB) stain and appeared blue. Conidial heads were large and radiate. Conidia appeared as pyriform to

globose structures. Hülle cells, which are produced to indicate the isolate's sexual potential, however, were not observed during the current study.

While studying the 3-dimensional structures of the wild-type and of the irradiated isolates of $A$. occultus MN259598 using Scanning Electron Microscopy, it revealed a conidiophore length of $1360 \mu \mathrm{m}$ (Fig. 4). In another instance (Fig. 5), the smooth-walled conidiophore was clearly visible with a length of $704 \mu \mathrm{m}$. This is a characteristic feature which was observed during both light microscopic studies and SEM analyses. In (Fig. 6), an enlarged and globose conidial head of the fungus with higher magnification is presented. The Scanning Electron Micrographic structure of irradiated A. occultus MN259598 species is being documented here for the first time, which showed severe architectural distortions of the fragmented vesicle and very poor formation of chains of conidia (Fig. 7) in comparison to the wild-type. Such ultrastructural studies have been rare, especially in context to nanoparticle production.

\subsection{Genetic characterization of the test fungal isolate}

In order to authenticate the identity of the fungal test isolate as Aspergillus occultus, DNA sequences which were generated by the PCR amplification of the ITS (Amplicon size: $594 \mathrm{bp}$ ) and $\beta$-tubulin genes (Amplicon size: $585 \mathrm{bp}$ ), were sequenced in the forward and reverse directions, compared with all known related sequences in the databanks and appropriate phylogenetic trees were constructed (Figs. 8 and 9). Phylogenetic trees were obtained by maximum parsimony (MP) and maximum likelihood (ML) methods, which yielded adequate results to examine the sensitivity of the resulting trees. Fungal phylogeny solely based on phenotypic characterization may not always elucidate the taxonomic status of the organisms in question [37]. Most certainly, the nuclear ribosomal DNA (rDNA) is the popular region in molecular studies because it is multi-copied and contains highly conserved genes [38]. Hence extensive morphological studies combined with nuclear-based molecular datasets provided valuable data in genus and species level identification of the fungal isolate under scrutiny. Due to many advantages like the ease of amplification and widespread use, ITS has been chosen as the official barcode for fungi by a consortium of mycologists $[39,40]$. 


\subsection{Synthesis Potentials of Wild-Type and Irradiated Fungal isolates of $A$. occultus MN259598}

CuONPs were synthesized from the cell-free extracts of the wild type and irradiated fungal specimens of A. occultus MN259598 with two different concentrations of Copper Acetate $(0.01 \mathrm{M}$ and $0.001 \mathrm{M})$ and Copper Nitrate $(0.001 \mathrm{M}$ and $0.005 \mathrm{M})$ as metal precursors. Nanoparticle sizes of $559 \mathrm{~nm}$ and $295 \mathrm{~nm}$ were obtained when tested with $0.001 \mathrm{M}$ concentration of Copper acetate and Copper nitrate respectively. Upon irradiation of $A$. occultus MN259598 with a dose of $1.33 \mathrm{~Gy}(2 \mathrm{kGy} / \mathrm{hr})$, a desirable size of $66.3 \mathrm{~nm}$ was achieved with $0.01 \mathrm{M}$ concentration of Copper acetate, whereas, the wild type strain showed a particle size distribution in the range of $150-300 \mathrm{~nm}$, where average particle size was found to be 362.82 $\mathrm{nm}$. On the other hand, the size of the nanoparticles was found to be $78-90 \mathrm{~nm}$ with culture filtrates of irradiated fungal specimen ( $\gamma$ irradiation dose rate: $3 \mathrm{kGy} / \mathrm{hr}$ ) treated with $0.005 \mathrm{M}$ concentration of Copper nitrate. In any case, variation in colour changes of the solution throughout the biological synthesis process was similar for both wild-type and irradiated strains. The use of gamma irradiation to successfully inactivate fungi in stored seeds [41], paper, wood and soil [42] etc., have been carried out in past. Although, the effect of Gamma irradiation has not been a part of extensive research when it comes to studying the toxigenic profile of different fungi. A study led by a research team [43] found a vast difference in mycotoxin production between irradiated and wild type strains of Aspergillus flavus and Aspergillus ochraceous, where, the irradiated strains showed heightened levels of Aflatoxin $\mathrm{B}_{1}$ and Ochratoxin, respectively. This can be explained as a stress response to stimulate excess toxin production. In another study [44], radiation doses of 2-10 kGy had been employed to inhibit Castor seed mycoflora. However, their application in bio-nanotechnology is being reported for the very first time in the current investigation. Irradiation adversely affected the membrane integrity and disrupted the fungal cell walls to a large extent resulting in the formation of malformed, stunted and thicker hyphae as compared to the slender mycelia observed with wild type specimens. Conidiophores showed severe fragmented appearance and were poorly developed. It is clear that the damage caused at the genetic level resulted in major mycelial distortions due to irradiation (because irradiated strains showed lower DNA concentration; data not shown here). Also, the extreme stress may have resulted in altered enzyme production leading to the formation of CuONPs in the size range of $66 \mathrm{~nm}$ and 78 to $90 \mathrm{~nm}$ as opposed to the approximate size range of $300 \mathrm{~nm}$ in case of wild-type specimens.

\subsection{Characterization of the Nanoparticles 5.4.1 UV-Vis Spectroscopic studies}

The formation of the metal nanoparticles namely CuONPs/ CuNPs was confirmed by UV-Vis Spectra as illustrated in (Fig. 10). Peaks were obtained with a maximum absorption at wavelengths of $245-295 \mathrm{~nm}$ for wild type and $243 \mathrm{~nm}, 295 \mathrm{~nm}$ for irradiated fungal isolates. This is an indication of inter-band transition of electrons in the core Copper metal. The results obtained in the current study were in accordance with previous reports published on CuONPs/ CuNPs [35]. In a specific study by [45], the shape of the spectra and the wavelength at which maximum absorbance occurs are strongly related to particle 
size and relative dimensions. It was also observed that there was a gradual decrease in the absorbance especially in the irradiated specimens. As and when the irradiation dose was increased, the frequency of the reduction of metal ions to metal nanoparticles showed a sequential diminishment. Although, the exact mechanism for reduction of Copper ions to Copper nanoparticles by test fungal isolate Aspergillus occultus MN259598 is unclear, irradiation may be used as a tool to achieve synthesis of nanoparticles in the nano-range (below $100 \mathrm{~nm}$ or lesser). Further, irradiation served to selectively eliminate the formation of larger particles as seen in non-irradiated samples (Fig. 11a-b).

\subsubsection{Dynamic Light Scattering analysis}

DLS data were taken in order to determine the particle size and the distribution of the CuONPs in a measurable size range, produced by biological methods. Differences in particle sizes were observed when varying concentrations of metal precursors were used. The average sizes of the particles formed by the wild-type fungal isolate were found to be $362.82 \mathrm{~nm}$ and $615 \mathrm{~nm}$ when $0.01 \mathrm{M}$ and $0.001 \mathrm{M}$ concentrations were respectively used. On the other hand, irradiated fungal specimens produced nanoparticles in the size range of 120.5 to $201.9 \mathrm{~nm}$ when radiation doses ranged from 1-3 kGy with optimum dosage ( $2 \mathrm{kGy}$ ), producing nanoparticles in the size of $66.3 \mathrm{~nm}$. Concentration of the metal precursor salt used, has a significant role in controlling the nanoparticle size along with other process parameters [46] like $\mathrm{pH}$, medium used for extraction, temperature, duration of the reaction time, etc. Size control of nanoparticles synthesized using fungal specimens demand a control of several parameters like rotary conditions during the growth of the organisms, $\mathrm{pH}$, etc. The whole focus in the current inquiry was the use of irradiation as one of the predominant parameters on studying the impact on the nanoparticle synthesis potential of the fungal isolate at a given set of parameters (Temperature $-30^{\circ} \mathrm{C} ; \mathrm{pH}$ 7)

\subsubsection{SEM analysis}

Several studies have reported the shape and size of Copper/ Copper oxide [47] and other metal nanoparticles [48, 49] using fungi. Surface morphology using Scanning Electron Microscopic (SEM) studies revealed polygonal particles with rounded ends and exhibited polydispersity, with diameters ranging in size from 60-200 nm (Fig. 12a-b), as against particle size ranging from 500-600 nm with non-irradiated samples, achieved with extracellular synthesis using the mycelium-free fungal extract of the isolate $A$. occultus MN259598. Both, individual particles and tiny aggregates were observed.

\subsubsection{FTIR analysis}

FTIR analysis was carried out for the biosynthesized CuNPs to deduce the presence or absence of specific functional groups present on them. The IR spectrum of the CuNPs showed peaks at $3421 \mathrm{~cm}^{-1}$, $2925 \mathrm{~cm}^{-1}, 1618 \mathrm{~cm}^{-1}, 1398 \mathrm{~cm}^{-1}, 1050 \mathrm{~cm}^{-1}, 548 \mathrm{~cm}^{-1}$ and $457 \mathrm{~cm}^{-1}$ which correspond to $\mathrm{H}$-bonded stretching in $\mathrm{O}-\mathrm{H}$ group, $\mathrm{C}-\mathrm{H}$ asymmetrical stretch vibration of alkanes, bending vibration of $\mathrm{N}-\mathrm{H}$ bond, $\mathrm{OH}$ bending of tertiary alcohols, C-O stretch of primary alcohol, C-halogen stretching vibration and S-S stretch of aryl disulfides respectively $[50,51]$. The broad band at $3421 \mathrm{~cm}^{-1}$ is in the range $3400-3200 \mathrm{~cm}^{-1}$, specifying the $\mathrm{H}$-bonded stretching in $\mathrm{O}-\mathrm{H}$ which is for the presence of hydroxyl groups in fungal culture extracts. The two peaks 2855 and 2925 are assigned to $\mathrm{C}-\mathrm{H}$ stretching in- $\mathrm{CH}_{3}$ and $\mathrm{CH}_{2}$ groups 
respectively. According to [52], the above two peaks 2855 and 2925 mainly show the presence of lipid molecules. The FTIR spectra containing peaks 1398 and $1050 \mathrm{~cm}^{-1}$ can be assigned to $-\mathrm{OH}$ bend of tertiary alcohols and $\mathrm{C}-\mathrm{O}$ stretch of primary alcohols, which clearly confirm that the oxygen-containing groups such as hydroxyl, epoxy and carboxyl groups are successfully bound to the surface of nanoparticles due to oxidation. The bands $1618 \mathrm{~cm}^{-1}$ and $457 \mathrm{~cm}^{-1}$ are due to the appearance of bending vibrations of $\mathrm{N}-\mathrm{H}$ bonds present in primary, secondary amines and S-S stretching vibration in disulphide bonds respectively $[50,51]$. Based on the above FTIR data, it is clear that mainly lipids and proteins influence the synthesis and stabilization of nanoparticles. It confirms the presence of the proteins and lipids that have been secreted (Fig. 13) by the test isolate Aspergillus occultus MN259598 which could contribute to the formation of nanoparticles as well as their stabilization [53].

\subsubsection{X-Ray Diffraction Studies}

Powder X-ray Diffraction (XRD) of synthesized NPs was carried out which authenticated these structures to be of Cu NPs. The XRD spectrum showed formation of broader peak with less intensity. Such a pattern supported the fact that the NPs under study are composed of small crystals. The size of the NP plays a pivotal role in determining the crystalline structure of NPs. The peaks observed at $2 \theta$ (Bragg reflections) values of $43.08^{\circ}, 50.23^{\circ}$ and $73.91^{\circ}$ (Table 1) correspond to (111), (200) and (220) sets of lattice planes of metallic $\mathrm{Cu}$, which can be indexed to face-centered cubic (FCC) structure of copper $[54,55]$. XRD data that was obtained in this experiment was in well accordance with the Joint Committee of Powder Diffraction Standards (JCPDS) data to identify the crystallographic phases. These peaks were in exact resemblance with the JCPDS file number- 04-0836, which ultimately proved the formation of nanocrystals of copper $(\mathrm{Cu})$ in the biological nanoparticle sample (Fig. 14).

\subsubsection{Antimicrobial assays against Food-borne pathogenic bacteria}

The well diffusion method was used, in order to determine the effects of the CuNPs (from wild-type and irradiated fungal isolates) against three different genera namely $E$. coli, B. cereus and L. monocytogenes. The zones of inhibition ( $\mathrm{mm}$ ) obtained are presented in the (Fig. 15a-c). In the case of E. coli and $L$. monocytogenes, the nanoparticles produced from irradiated fungal isolate Aspergillus occultus MN259598 showed better inhibition rates. Such studies using wild-type and irradiated isolates, comparing their synthesis potentials and the effects on pathogenic bacteria is being reported for the very first time. This is also ascribed to the reduction in size of the nanoparticles which was achieved through irradiation. While size of the nanoparticle can have a significant bearing on its antimicrobial effect [56], extensive studies are required to explain this phenomenon in adequate detail. One of the rationales is the distinction between the Gram-negative and Gram-positive bacteria, with respect to their cell wall structure and thickness, making the former more vulnerable to nanoparticle exposure and inhibitory effect. Although, the Gram-positive bacteria lack an outer membrane, they are surrounded by a thicker peptidoglycan layer [57, 58]. Few studies have reported the antimicrobial properties of CuNPs [59], and may have similar mechanism of action as that of silver. However, the precise mechanism regarding how CuNPs cause an inhibitory activity is unclear. It is thought that Copper acts by combining with the 
Sulfhydryl groups (-SH) of key microbial enzymes [60]. According to previous reports, studies on antibacterial effects of CuNPs are limited when compared to AgNPs or ZnONPs and higher concentrations of the NPs are required to achieve similar results. Some researchers [61] opine that copper being less expensive than other nanometals, can be utilized as nanocomposites for increasing antibiotic efficiency.

\section{Conclusions}

The synthesis of nanoparticles by biological routes is not only exciting for a researcher but also extremely challenging. The current era has seen a surge in nanotechnological studies pertaining to the use of especially fungi in nanoparticle synthesis and has emerged as a branch of science called Myconanotechnology. The use of Aspergillus occultus MN259598 in the current exploration was novel, because, scientific reports involving this organism with special reference to Gamma ( $\nabla$ ) irradiation, being used to determine nanoparticle synthesis potentials are being reported for the very first time. Irradiation of the fungal test isolate was one of the foci, in order to study the excruciating effect on the phenotype of the fungal organism and the role of Gamma ( $(\mathbb{Z})$ irradiation on the NP synthesis potentials of the same. The study revealed that irradiation of the fungal isolate Aspergillus occultus MN259598 caused a drastic reduction in the size of the nanoparticles. This study also provided specific insights to reveal that Aspergilli, such as the fungal isolate used, could survive radiations up to $3 \mathrm{KGy} /$ hour. Although, severe phenotypic malformations were observed in their structural/ hyphal architecture (as evident by microscopic studies), nanoparticle synthesis was still achievable. Characterization studies of nanoparticles were especially helpful in order to determine features like type, purity, size distribution, dispersive nature, etc. Nanoparticles produced by such methods could be used in the production or design of drugs, in food-preservation techniques and development of biopesticides for agriculture. Further, evidence-based studies to deduce the pathways involving the enzymatic reduction of metal ions to metal nanoparticles, are the need of the hour to understand the complex mechanisms of nanoparticle synthesis in fungi.

\section{Declarations}

\section{Ethics approval and consent to participate}

This manuscript contains no animal research, no human studies, and no potentially identifiable human photos or data.

\section{Consent for publication}

Each author confirms that the publisher has obtained the author's consent to publish research findings.

\section{Availability of data and materials}


Internationally recognized scientific procedures were employed, and all data supporting the findings in the article should be widely available following publication. The datasets analyzed in this study are publicly available.

\section{Competing interests}

The authors state that no commercial or financial ties that might be considered as a potential conflict of interest existed during the conduct of the research.

\section{Funding}

We all certify that we receive no commercial or financial support from any source and that our work is carried out as Pondicherry University students. Authors are responsible for paying the APC costs with their own funds.

\section{Authors' contributions}

$\mathrm{RM}$ and RD were involved in planning and designing the research study. RM designed and conducted the experiments, analyzed the data, and drafted the manuscript. RD created the results, drafted the article, corrected errors, and aided in the manuscript's preparation. PM carried out the phylogenetic analysis, whilst MG carried out the experiments and drafted the article. The paper was written by all authors and their contributions were approved before to submission.

\section{Acknowledgements}

Services provided by Pondicherry University's Central Instrumentation Facility are universally acknowledged. PM thanks Pondicherry University for such Non-NET University Fellowship and expresses his gratitude.

\section{Authors' information (optional)}

Rathijit Mallick

Fungal Genetics and Mycotoxicology Laboratory, Department of Microbiology, School of Life Sciences, Pondicherry University, Puducherry, 605014, India

Email ID: rathijitmallick@gmail.com

Regina Sharmila Dass

Fungal Genetics and Mycotoxicology Laboratory, Department of Microbiology, School of Life Sciences, Pondicherry University, Puducherry, 605014, India

${ }^{1}$ Corresponding Author; Email ID: reginadass@gmail.com, 9629305471 and 
ORCID: 0000-0001-6838-2445

Pranab Kumar Mahata

Fungal Genetics and Mycotoxicology Laboratory, Department of Microbiology, School of Life Sciences, Pondicherry University, Puducherry, 605014, India

Email ID: pranabmahata22@gmail.com

Mayukhmita Ghose

Fungal Genetics and Mycotoxicology Laboratory, Department of Microbiology, School of Life Sciences, Pondicherry University, Puducherry, 605014, India

Email ID: mayukhmitaghose@gmail.com

\section{References}

1. Zhang W, Du Y, Wang ML. On-chip highly sensitive saliva glucose sensing using multilayer films composed of single-walled carbon nanotubes, gold nanoparticles, and glucose oxidase. Sens. BioSens Res. 2015;4:96-102. <background-color:\#CFBFB1;uverticalalign:super;>https://doi.org/10.1016/j.sbsr.2015.04.006s</background-color:\#CFBFB1;uverticalalign:super;><uvertical-align:super;>></uvertical-align:super;>

2. Gao W, Emaminejad S, Nyein HY, Challa S, Chen K, Peck A, et al. Fully integrated wearable sensor arrays for multiplexed in situ perspiration analysis. Nature. 2016;529:509-14. https://doi.org/10.1038/nature16521.

3. Gaggelli E, Kozlowski H, Valensin D, Valensin G. Copper homeostasis and neurodenegenerative disorders (Alzheimer's, prion and Parkinson's diseases and amyotrophic lateral sclerosis). Chem Rev. 2006;106:1995-2044. https://doi.org/10.1021/cr040410w.

4. Lutsenko S, Bhattacharjee A, Hubbard AL. Copper handling machinery of the brain. Metallomics. 2010;2:596-608. https://doi.org/10.1039/c0mt00006j.

5. Evans GW. Copper homeostasis in the mammalian system. Physiol Rev. 1973;53:535-70. https://doi.org/10.1152/physrev.1973.53.3.535.

6. Sternlieb I. Copper and the liver. Gastroenterol. 1980;78:1615-28. https://doi.org/10.1016/S00165085(19)30524-4.

7. Bonham M, O'Connor JM, Hannigan BM, Strain JJ. The immune system as a physiological indicator of marginal copper status? Bri J Nut. 2002;87:393-403. https://doi.org/10.1079/BJN2002558.

8. Davis TA, Volesky B, Mucci A. A review of the biochemistry of heavy metal biosorption by brown algae. Water Res. 2003;37:4311-30. https://doi.org/10.1016/S0043-1354(03)00293-8.

9. Araya M, Olivares M, Pizarro F. Copper in human health. Int J Environ Health. 2007;1:608-20. doi/abs/10.1504/IJENVH.2007.018578. 
10. Raffi M, Mehrwan S, Bhatti TM, Akhter Jl, Hameed A, Yawar W. Investigations into the antibacterial behavior of copper nanoparticles against Escherichia coli. Ann Microbiol. 2010;60:75-80. https://doi.org/10.1007/s13213-010-0015-6.

11. Rispoli F, Angelov A, Badia D, Kumar A, Seal S, Shah V. Understanding the toxicity of aggregated zero valent copper nanoparticles against Escherichia coli. J Hazard Mater. 2010;180:212-6. https://doi.org/10.1016/j.jhazmat.2010.04.016.

12. Yoon KY, Byeon JH, Park JH, Hwang J. Susceptibility constants of Escherichia coli and Bacillus subtilis to silver and copper nanoparticles. Sci Total Environ. 2007;373:572-5. <backgroundcolor:\#CFBFB1;bu>https://doi.org/10.1016/j.scitotenv.2006.11.007</backgroundcolor:\#CFBFB1;bu>.

13. Bigdeli A, Ghasemi F, Golmohammadi H, Abbasi-Moayed S, Nejad MA, Fahimi-Kashani N, et al. Nanoparticle-based optical sensor arrays. Nanoscale. 2017;9:16546-63. https://doi.org/10.1039/C7NR03311G.

14. Hirsch LR, Stafford RJ, Bankson JA, Sershen SR, Rivera B, Price RE, et al. Nanoshell-mediated nearinfrared thermal therapy of tumors under magnetic resonance guidance. Proc Natl Acad Sci. 2003;100:13549-54. https://doi.org/10.1073/pnas.2232479100.

15. Gyawali R, Ibrahim SA, Abu Hasfa SH, Smqadri SQ, Haik Y. Antimicrobial activity of copper alone and in combination with lactic acid against Escherichia coli $0157: \mathrm{H} 7$ in laboratory medium and on the surface of lettuce and tomatoes. J Pathog. 2011;2011. https://doi.org/10.4061/2011/650968.

16. Bhushan B. Springer Handbook of Nanotechnology. Therapeutic Nanodevices. 2004; Chap. 10. http://dx.doi.org/10.1007/3-540-29838-X.

17. Singh P, Kim YJ, Zhang D, Yang DC. Biological synthesis of nanoparticles from plants and microorganisms. Trends Biotechnol. 2016;34:588 - 99.

https://doi.org/10.1016/j.tibtech.2016.02.006.

18. Shah M, Fawcett D, Sharma S, Tripathy SK, Poinern GE. Green synthesis of metallic nanoparticles via biological entities. Materials. 2015;8:7278-308. https://doi.org/10.3390/ma8115377.

19. Das SK, Dickinson C, Lafir F, Brougham DF, Marsili E. Synthesis, characterization and catalytic activity of gold nanoparticles biosynthesized with Rhizopus oryzae protein extract. Green Chem. 2012;14:1322-34. https://doi.org/10.1039/C2GC16676C.

20. Cuevas R, Durán N, Diez MC, Tortella GR, Rubilar O. Rubilar, Extracellular biosynthesis of copper and copper oxide nanoparticles by Stereum hirsutum, a native white-rot fungus from chilean forests. J Nanomater. 2015;2015. https://doi.org/10.31155/2015/789089.

21. Mohanpuria P, Rana NK, Yadav SK. Biosynthesis of nanoparticles: technological concepts and future applications. J Nanopart Res. 2008;10:507 - 17. https://doi.org/10.1007/s11051-007-9275-x.

22. Vigneshwaran N, Ashtaputre NM, Varadarajan PV, Nachane RP, Paralikar KM, Balasubramanya RH. Biological synthesis of Silver nanoparticles using the fungus Aspergillus flavus. Mater Lett. 2007;61:1413-8. https://doi.org/10.1016/j.matlet.2006.07.042. 
23. Li X, Xu H, Chen ZS, Chen G. Biosynthesis of nanoparticles by microorganisms and their applications. J Nanomat. 2011;2011. https://doi.org/10.1155/2011/270974.

24. Singh J, Dutta T, Kim KH, Rawat M, Samddar P, Kumar P. 'Green' synthesis of metals and their oxide nanoparticles: applications for environmental remediation. J Nanobiotechnology. 2018;16:1-24. https://doi.org/10.1186/S12951-018-0408-4.

25. McNamara NP, Black HI, Beresford NA, Parekh NR. Effects of acute gamma irradiation on chemical, physical and biological properties of soils. Appl Soil Ecol. 2003;24:117-32. https://doi.org/10.1016/S0929-1393(03)00073-8.

26. Borrely SI, Cruz AC, Del Mastro NL, Sampa MH, Somessari ES. Radiation processing of sewage and sludge, A review. Prog Nucl Energy. 1998;33:3-21. https://doi.org/10.1016/S0149-1970(97)87287-3.

27. Tubiana M, Dutreix J, Wambersie A. Introduction to radiobiology. Taylor and Francis, New York, USA, 1990.

28. World Health Organization. High-dose irradiation: wholesomeness of food irradiatied with doses above 10 kGy. WHO, Technical Report, Geneva, Switzerland, 1999.

29. Broomfield S, Hryciw T, Xiao W. DNA post-replication repair and mutagenesis in Saccharomyces cerevisiae. Mutation Res. 2001;486:167-84. https://doi.org/10.1016/s0921-8777(01)00091-x.

30. Jeong S, Woo K, Kim D, Lim S, Kim JS, Shin H, et al. Controlling the thickness of the surface oxide layer on Cu nanoparticles for the fabrication of conductive structures by ink-jet printing. Adv Funct Mater. 2008;18:679-86. https://doi.org/10.1002/adfm.200700902.

31. Raper KB, Fennell DI. The Genus Aspergillus. The Williams and Wilkins, Baltimore, Md, USA, 1965.

32. Frisvad JC, Petersen LM, Lyhne EK, Larsen TO. Formation of Sclerotia and production of Indoloterpenes by Aspergillus niger and other species in Section Nigri. Plos One. 2014;9:e94857. https://doi.org/10.1371/journal.pone.0094857.

33. Refai M, El-Yazid HA, Hassan A. Hassan, Monograph on Aspergillus and Aspergillosis in man, animals and birds. A guide for classification and identification of aspergilli, diseases caused by them, diagnosis and treatment. Academia. 2014.

34. Visagie CM, Varga J, Houbraken J, Meijer M, KocsubÚ S, Yilmaz N, et al. Ochratoxin production and taxonomy of the yellow aspergilli (Aspergillus Section Circumdati). Stud Mycol. 2014;78:1-61. https://doi:10.1016/j.simyco.2014.07.001.

35. Kumar PV, Shameem U, Kollu P, Kalyani RL, Pammi SV. Green synthesis of copper oxide nanoparticles using Aloe vera leaf extract and its antibacterial activity against fish bacterial pathogens. Bionanoscience. 2015;5:135-9. https://doi.org/10.1007/s12668-015-0171-z.

36. Usman MS, El Zowalaty ME, Shameli K, Zainuddin N, Salama M, Ibrahim NA. Synthesis, characterization, and antimicrobial properties of copper nanoparticles. Int J Nanomed. 2013;8:4467. https://doi.org/10.2147/ijn.s50837.

37. Berbee ML, Carmean DA, Winka K. Ribosomal DNA and resolution branching order among the ascomycota: how many nucleotides are enough? Mol Phylogenet Evol. 2000;17:337-44. https://doi.org/10.1006/mpev.2000.0835.

Page $18 / 33$ 
38. Raja HA, Miller AN, Pearce CJ, Oberlies NH. Oberlies, Fungal Identification using Molecular tools: A primer for the natural products Research Community. J Nat Prod. 2017;80:756-70. https://doi.org/10.1021/acs.jnatprod.6b01085.

39. Schoch CL, Seifert KA, Huhndorf S, Robert V, Spouge JL, Levesque CA, et al. Nuclear ribosomal internal transcribed spacer (ITS) region as a universal DNA barcode marker for Fungi. Proc Natl Acad Sci. 2012;109:6241-6. https://doi.org/10.1073/pnas.1117018109.

40. Buehler AJ, Evanowski RL, Martin NH, Boor KJ, Wiedmann M. Internal transcribed spacer (ITS) sequencing reveals considerable fungal diversity in dairy products. Int J Dairy Sci. 2017;100:881425. https://doi.org/10.3168/jds.2017-12635.

41. Jeong RD, Shin EJ, Chu EH, Park HJ. Effects of Ionizing Radiation on Postharvest Fungal Pathogens. Plant Pathol J. 2015;31:176. https://doi.org/10.5423/ppj.nt.03.2015.0040.

42. da Silva M, Moraes AM, Nishikawa MM, Gatti MJ, de Alencar MV, Brandão LE, et al. Inactivation of fungi from deteriorated paper materials by radiation. Int Biodeterior Biodegradation. 2006;57:163-7. https://doi.org/10.1016/j.ibiod.2006.02.003.

43. Ribeiro J, Cavaglieri L, Vital H, Cristofolini A, Merkis C, Astoreca A, et al. Effect of gamma radiation on Aspergillus flavus and Aspergillus ochraceous ultrastructure and mycotoxin production. Radiat Phys Chem. 2011;80:658-63. https://doi.org/10.1016/j.radphyschem.2010.12.017.

44. Kobori NN, Mastrangelo T, Cicero SM, Cassieri P, Moraes MH, Walder JM. Effects of Gamma irradiation on physiological and phytosanitary qualities of Brazilian castor bean seeds, Ricinus communis (cv. IAC Guarani). Res J Seed Sci. 2010;3:70-81.

45. Kumar DA, Palanichamy V, Roopan SM. Green synthesis of silver nanoparticles using Alternanthera dentata leaf extract at room temperature and their antimicrobial activity. Spectrochim Acta A Mol Biomol Spectrosc. 2014;127:168-71. https://doi.org/10.1016/j.saa.2014.02.058.

46. Gahlawat G, Choudhury AR. A review on the biosynthesis of metal and metal salt nanoparticles by microbes. RSC Adv. 2019;9:12944-67. https://doi.org/10.1039/c8ra10483b.

47. Tiwari M, Narayanan K, Thakar MB, Jagani HV, Rao JV. Biosynthesis and wound healing activity of copper nanoparticles. IET Nanobiotechnol. 2014;8:230-7. https://doi.org/10.1049/ietnbt.2013.0052.

48. Duran N, Marcato PD, Ingle A, Gade A, Rai M. Fungi mediated synthesis of silver nanoparticles: characterization processes and applications, in Progress in Mycology, M. Rai and G. Kövics, Eds., Scientific Publishers, Jodhpur, India. 2010;342:425-29.

49. Durán N, Marcato PD, Durán M, Yadav A, Gade A, Rai M. Mechanistic aspects in the biogenic synthesis of extracellular metal nanoparticles by peptides, bacteria, fungi, and plants. Appl Microbiol Biotechnol. 2011;90:1609-24. doi: 10.1007/s00253-011-3249-8.

50. Larkin P. Infrared and Raman spectroscopy: Principles and spectral interpretation. Elsevier, 2017.

51. Movasaghi Z, Rehman S, ur Rehman DI. Fourier transform infrared (FTIR) spectroscopy of biological tissues, Appl Spectrosc Rev. 2008;43:134-79. https://doi.org/10.1080/05704920701829043. 
52. Forfang K, Zimmermann B, Kosa G, Kohler A, Shapaval V. FTIR Spectroscopy for evaluation and monitoring of lipid extraction efficiency for oleaginous fungi. PLoS One. 2017;12:e0170611. https://doi.org/10.1371/journal.pone.0170611.

53. Shah M, Fawcett D, Sharma S, Tripathy SK, Poinern GE. Green Synthesis of Metallic Nanoparticles via Biological Entities. Materials. 2015;8:7278-308. https://doi.org/10.3390/ma8115377.

54. Betancourt-Galindo R, Reyes-Rodriguez PY, Puente-Urbina BA, Avila-Orta CA, Rodríguez-Fernández OS, Cadenas-Pliego G, et al. Synthesis of Copper nanoparticles by thermal decomposition and their antimicrobial properties. J Nanomater. 2014;2014. https://doi.org/10.1155/2014/980545.

55. Park BK, Jeong S, Kim D, Moon J, Lim S, Kim JS. Synthesis and size control of monodisperse copper nanoparticles by polyol method. J Colloid Interface Sci. 2007;311:417-24. https://doi.org/10.1016/j.jcis.2007.03.039.

56. Caroling G, Vinodhini E, Ranjitham AM, Shanthi P. Biosynthesis of Copper nanoparticles using aqueous Phyllanthus emblica (Gooseberry) extract-Characterisation and study of antimicrobial effects. Int J Nano Chem. 2015;1:53-63. https://doi.org/10.12785/ijnc/010203.

57. Silhavy TJ, Kahne D, Walker S. The bacterial cell envelope. Cold Spring Harb Perspect Biol. 2010;2:a000414. https://doi.org/10.1101/cshperspect.a000414.

58. Longano D, Ditaranto N, Cioffi N, Di Niso F, Sibillano T, Ancona A, et al. Analytical characterization of laser-generated copper nanoparticles for antibacterial composite food packaging. Anal Bioanal Chem. 2012;403:1179-86. https://doi.org/10.1007/s00216-011-5689-5.

59. Hajipour MJ, Fromm KM, Ashkarran AA, de Aberasturi DJ, de Larramendi IR, Rojo T, et al. Antibacterial properties of nanoparticles. Trends Biotechnol. 2012;30:499-511. https://doi.org/10.1016/j.tibtech.2012.06.004.

60. Allaker RP, Memarzadeh K. Nanoparticles and the control of oral infections. Int J Antimicrob Agents. 2014;43:95-104. https://doi.org/10.1016/j.ijantimicag.2013.11.002.

61. Beyth N, Houri-Haddad Y, Domb A, Khan W, Hazan R. Alternative antimicrobial approach: Nanoantimicrobial materials. Evid-based Complement Altern Med. 2015;2015. https://doi.org/10.1155/2015/246012.

\section{Tables}

Table 1 is not available with this version.

\section{Figures}



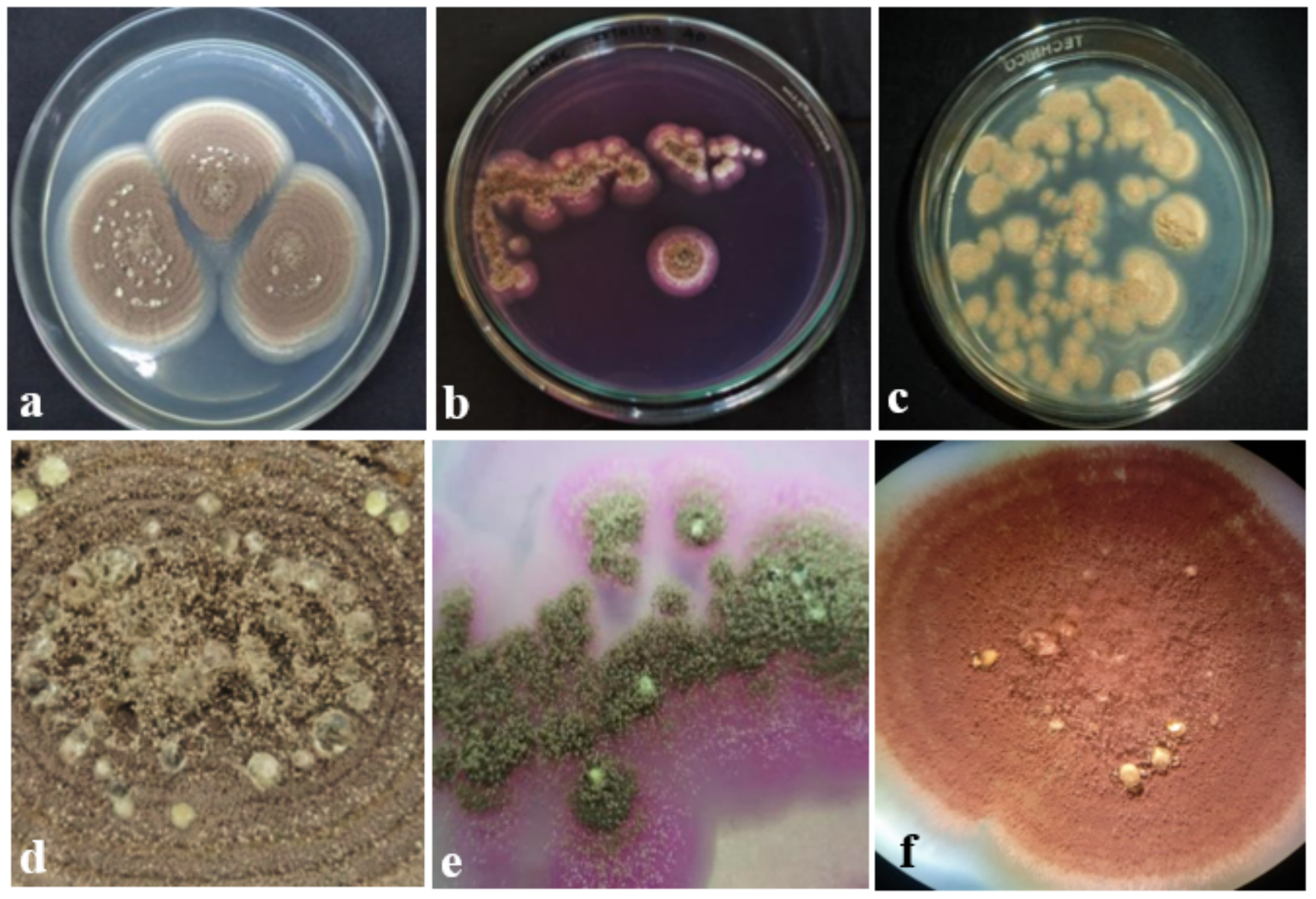

\section{Figure 1}

Macromorphological observation of Aspergillus occultus MN259598 on (a) synthetic PDA, (b) DRBC and (c) Fungal agar medium with naked eye observation on the top panel. (d), (e), (f), Bottom panel shows the corresponding stereomicroscopic observation at 10X (Flow of images: Top to bottom)
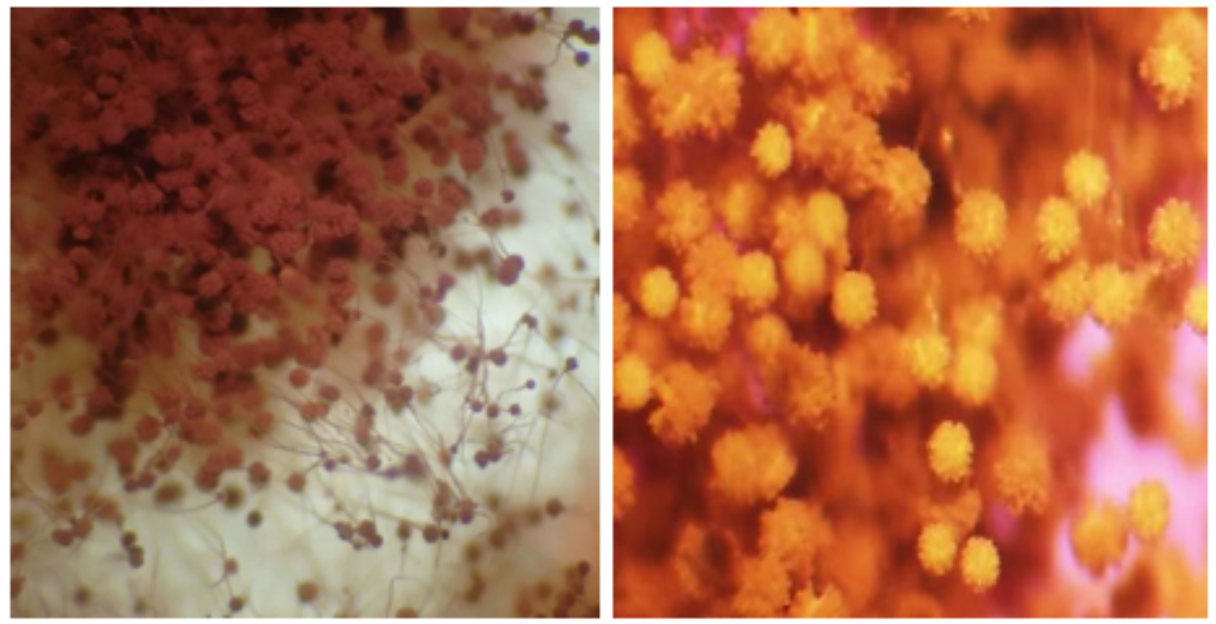

Figure 2 
Stereo binocular microscopic obverse view of a colony of $A$. occultus MN259598 showing conidial heads $(20 \mathrm{X})$
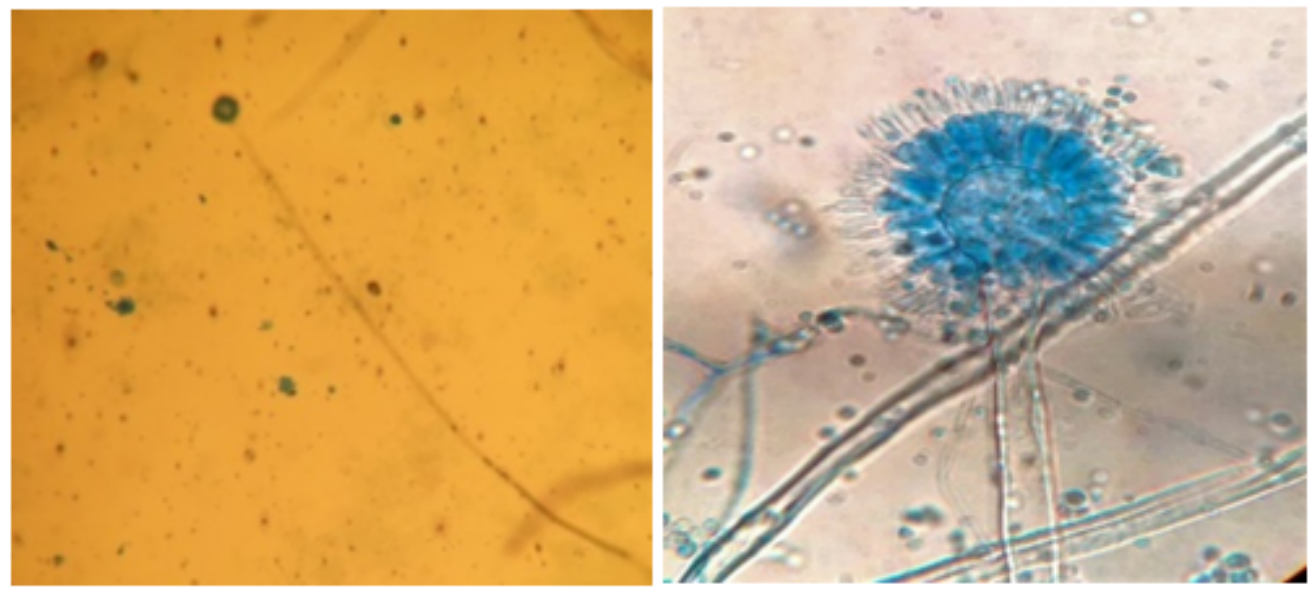

\section{Figure 3}

Light microscopic image of a young and mature, unusually long conidial head of $A$. occultus MN259598 enlarged (left). The right-hand side image is showing the sterigmata at 40X magnification.
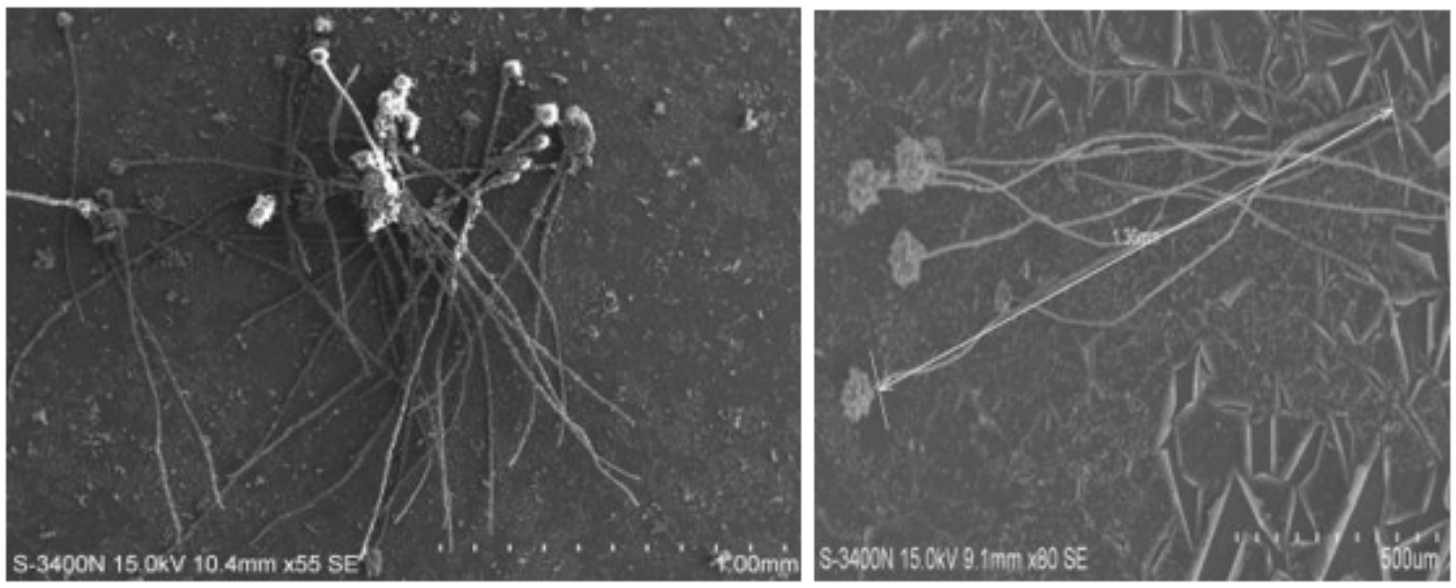

\section{Figure 4}

Scanning Electron Microscopic image showing a tuft of conidiophores and length measurement of the longest conidiophore $(1360 \mu \mathrm{m})$ of $A$. occultus MN259598. 


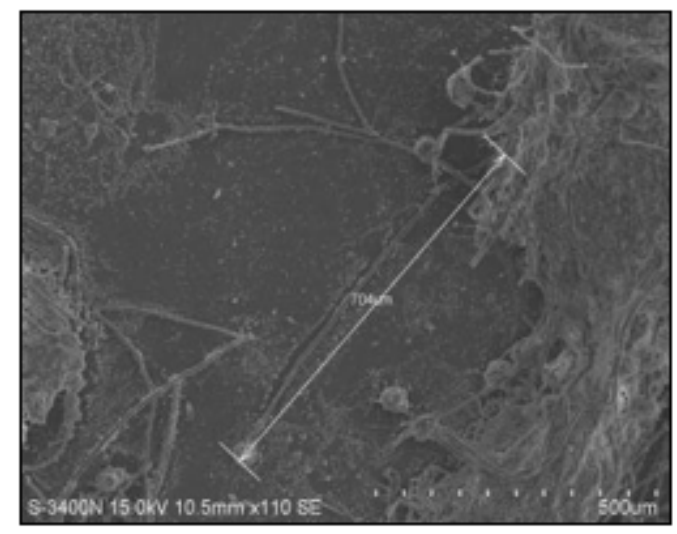

Figure 5

Conidiophore of $A$. occultus MN259598 scanned by SEM at $704 \mathrm{~nm}$ resolution.

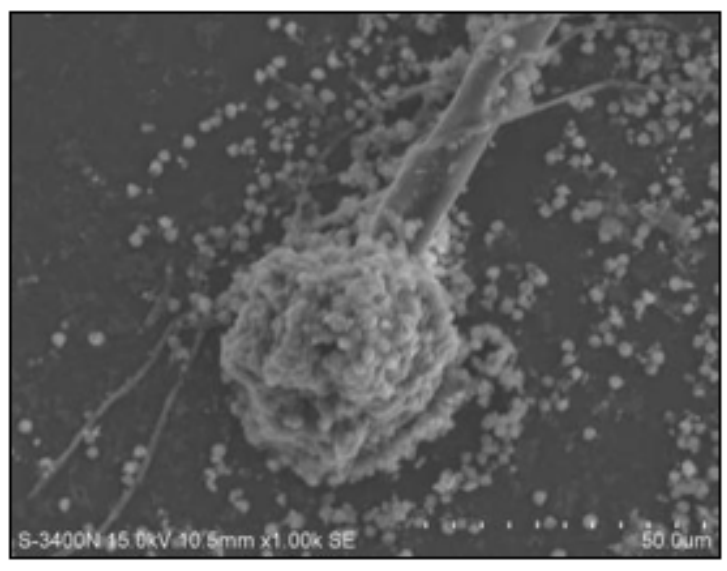

Figure 6

SEM image of an enlarged, globose conidial head of $A$. occultus MN259598 at higher magnification. 

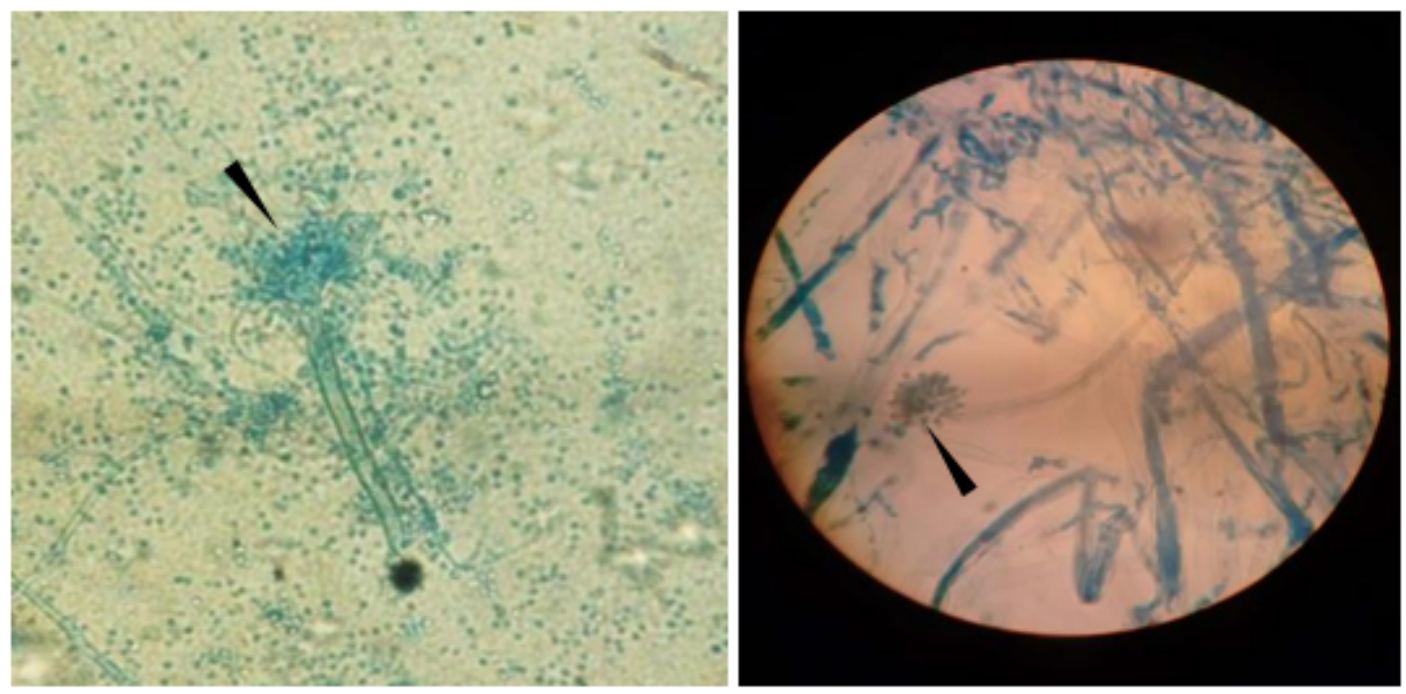

Figure 7

Following irradiation, light microscopic pictures showed architectural (conidiophore) deformities in $A$. occultus MN259598. The light microscopic images demonstrate inadequate conidial chain formation, fragmented vesicles, and spore dispersion throughout the field (shown by a black triangle-shaped indication). 
ITS

MP/ML

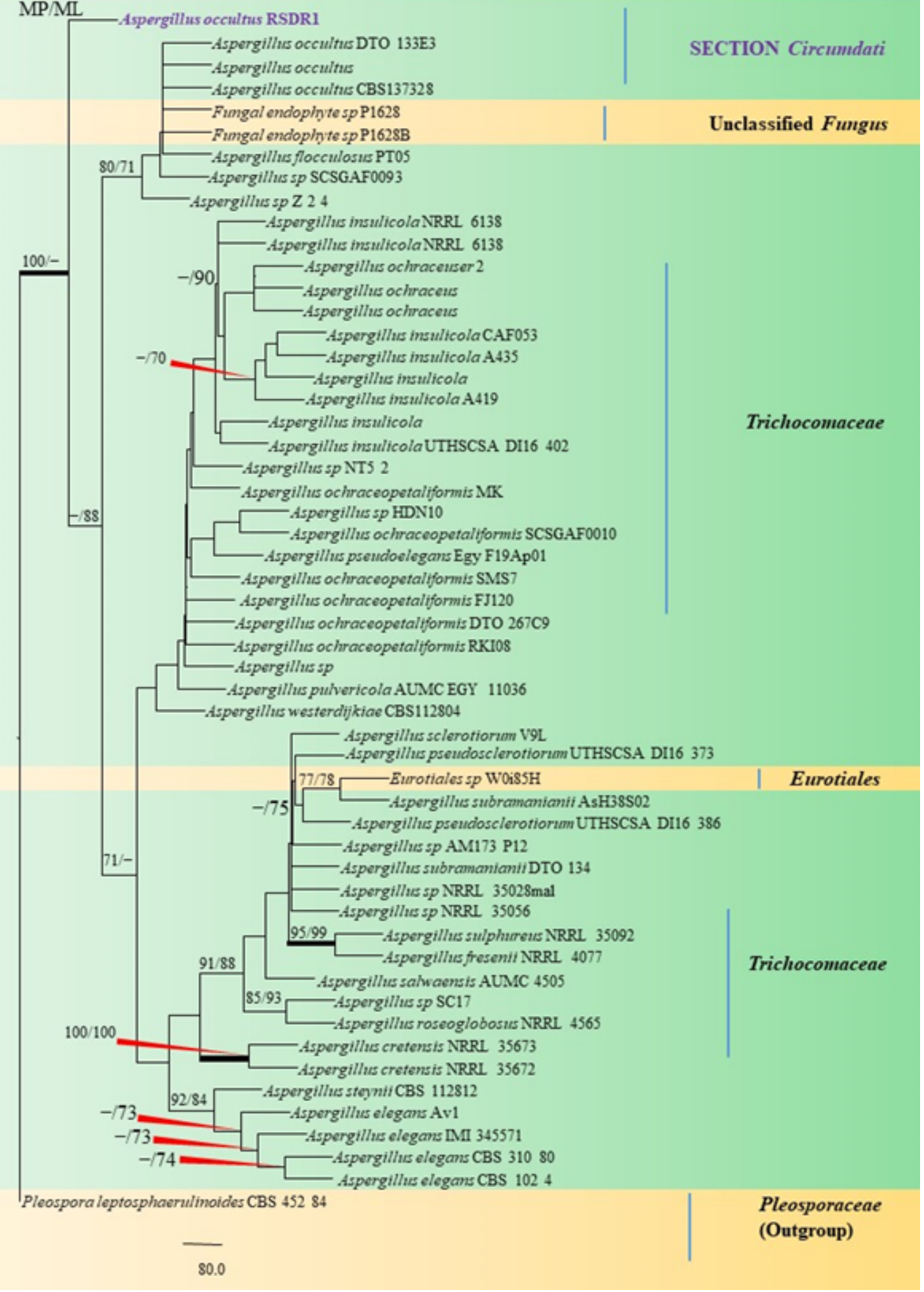

\section{Figure 8}

A phylogenetic tree (taxon branching diagram) which presents the genetic analysis of the Aspergillus occultus RSDR2 clade belonging to the Section Circumdati, exhibiting a maximum parsimony analysis of partial ITS1 and ITS4 concatenated sequences, acquired. 


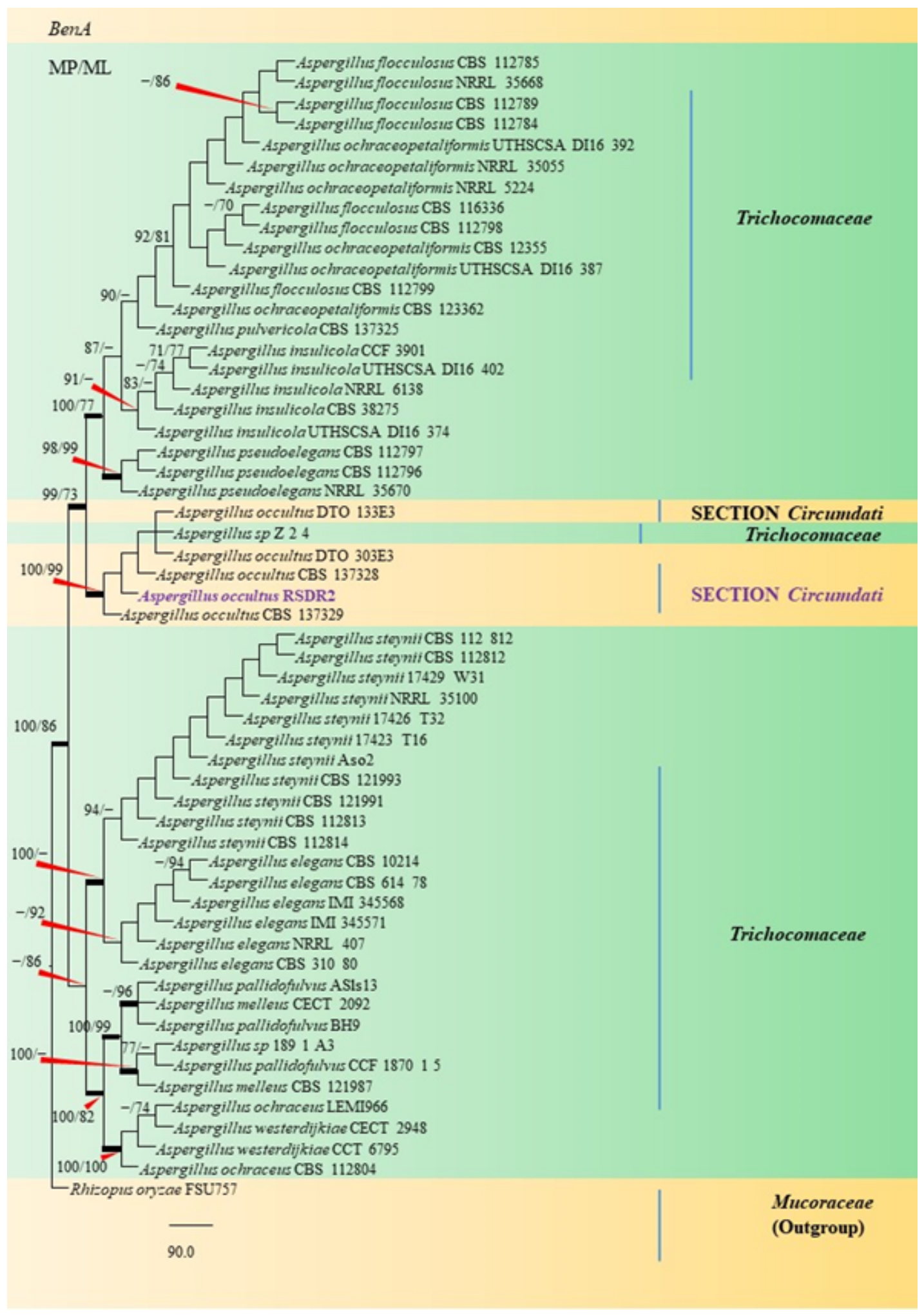

\section{Figure 9}

A phylogenetic tree (taxon branching diagram) which presents the genetic analysis of the Aspergillus occultus RSDR2 clade belonging to the Section Circumdati, exhibiting a maximum parsimony analysis of partial $\beta$-tubulin concatenated sequences, acquired. 


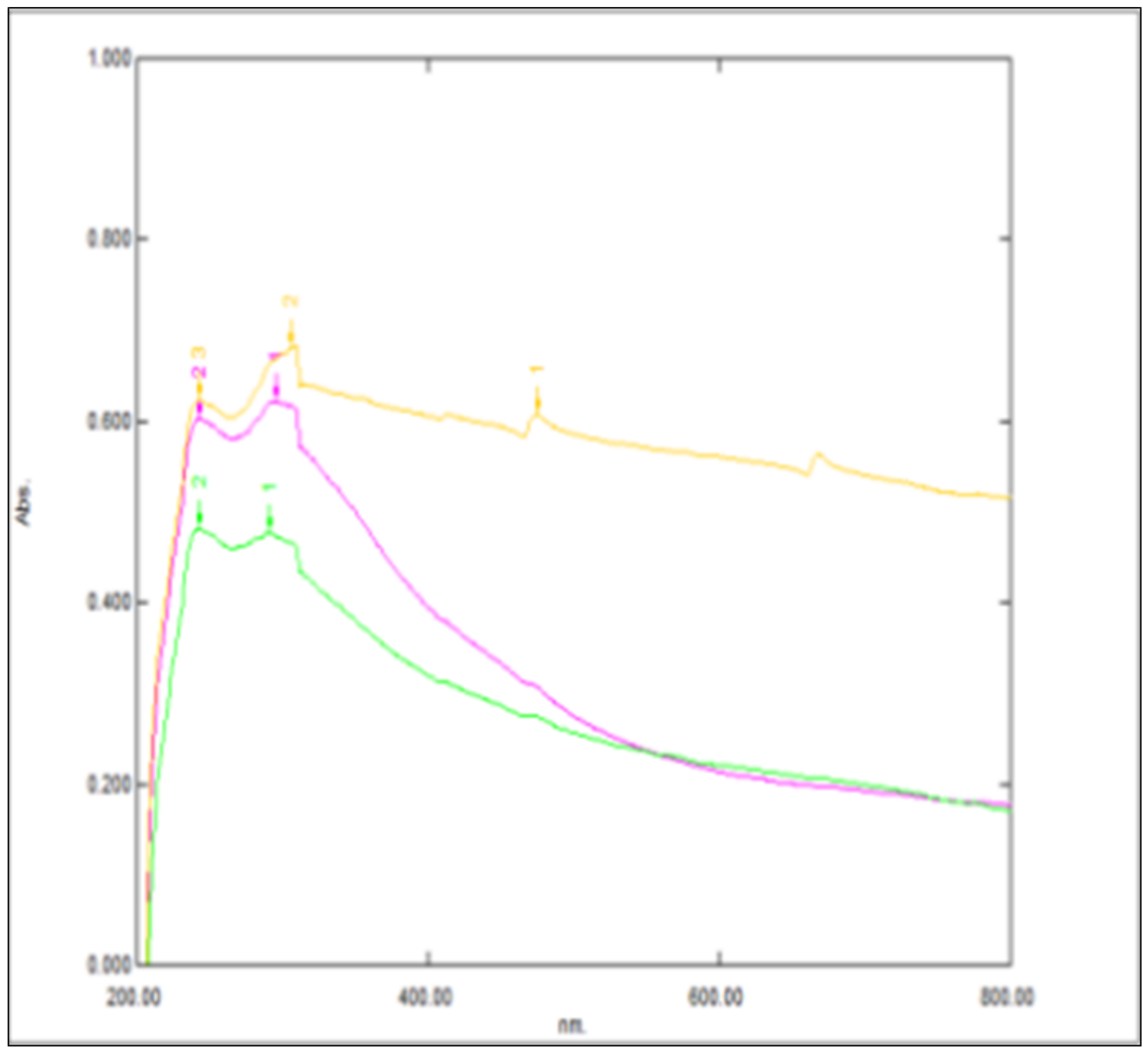

Figure 10

UV-Vis spectra showing the absorption maximum of the CuNPs of both wild type and irradiated samples. Wavelength range of CuONPs synthesized from wild type Aspergillus sp. SR2927 indicated by yellow line showing peaks in the range of 200-400. CuONPs synthesized from gamma irradiated strain showed peaks at 243 and $295 \mathrm{~nm}$ indicated by green line. (Violet color line represents data from another experiment). 


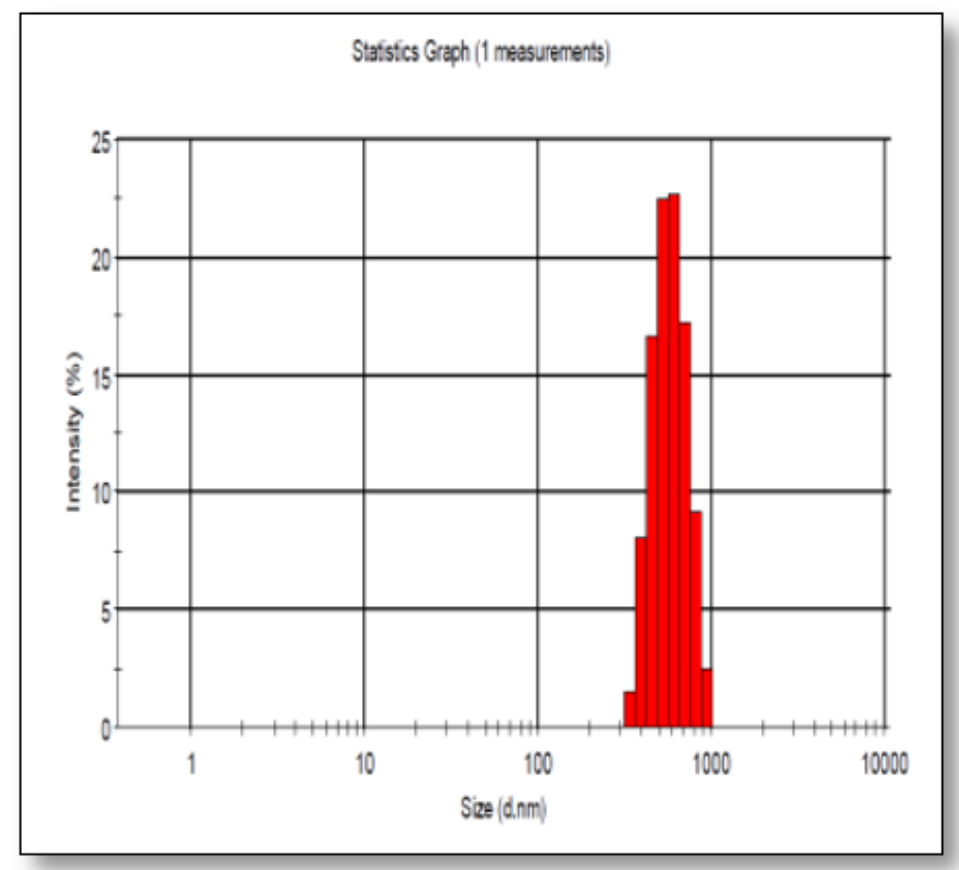

a

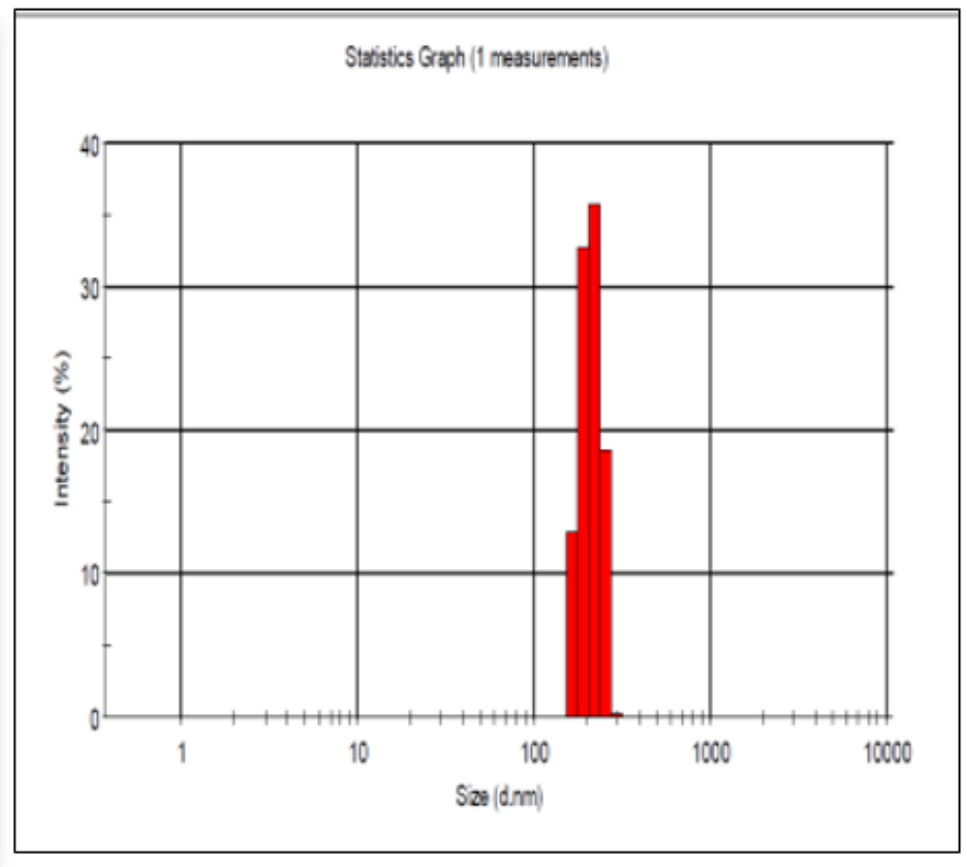

b

Figure 11

Graph reflecting the dynamic light scattering (DLS) properties of the formed CuNPs from (a) PDB in a size range of $559 \mathrm{~nm}$. (CuA- $0.01 \mathrm{M}$ ). Histogram showing analysis of particle distribution by DLS of the (b) biologically synthesized CuNPs $(0.01 \mathrm{M})$ from the wild type $A$. occultus strain MN259598. Polydispersity of particles were observed in the range of $150-300 \mathrm{~nm}$ approximately. 


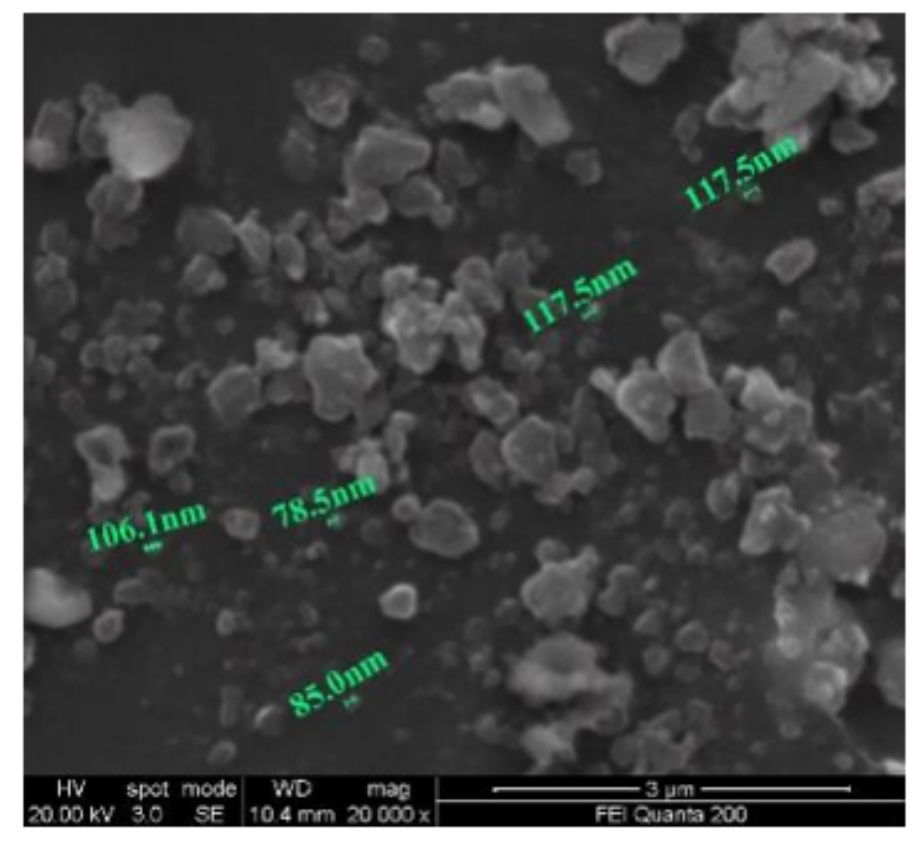

a

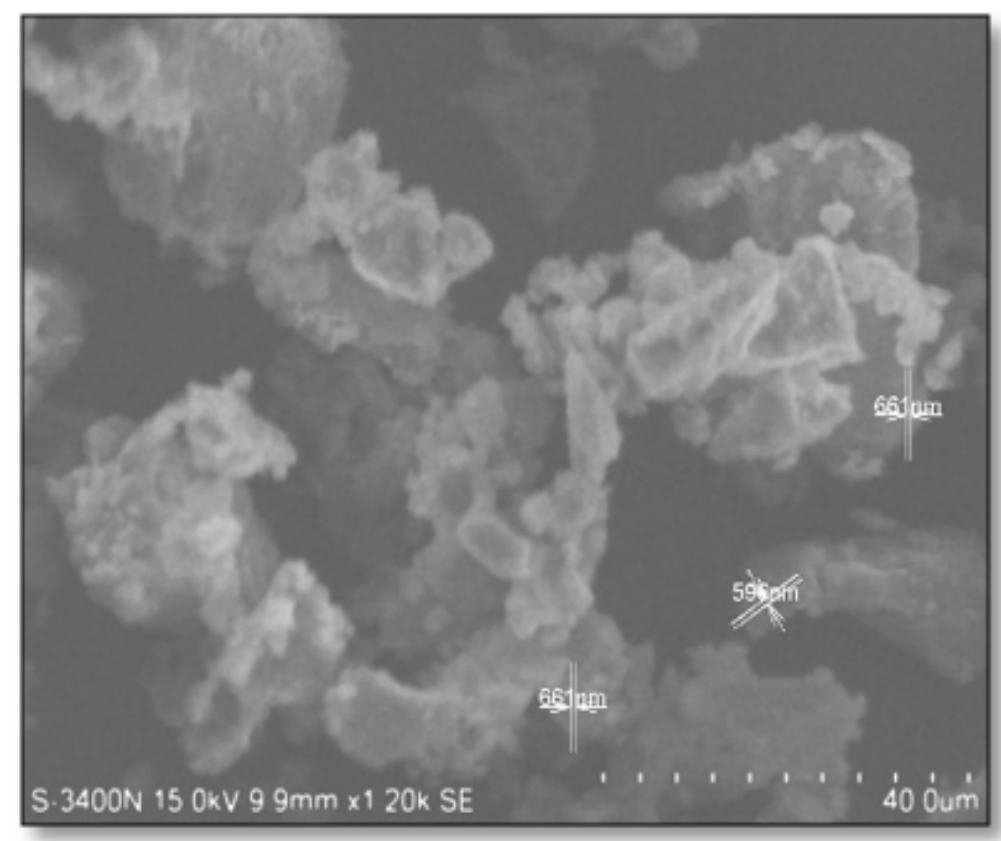

b

\section{Figure 12}

(a), (b) Scanning Electron Micrographs of Copper nanoparticles 


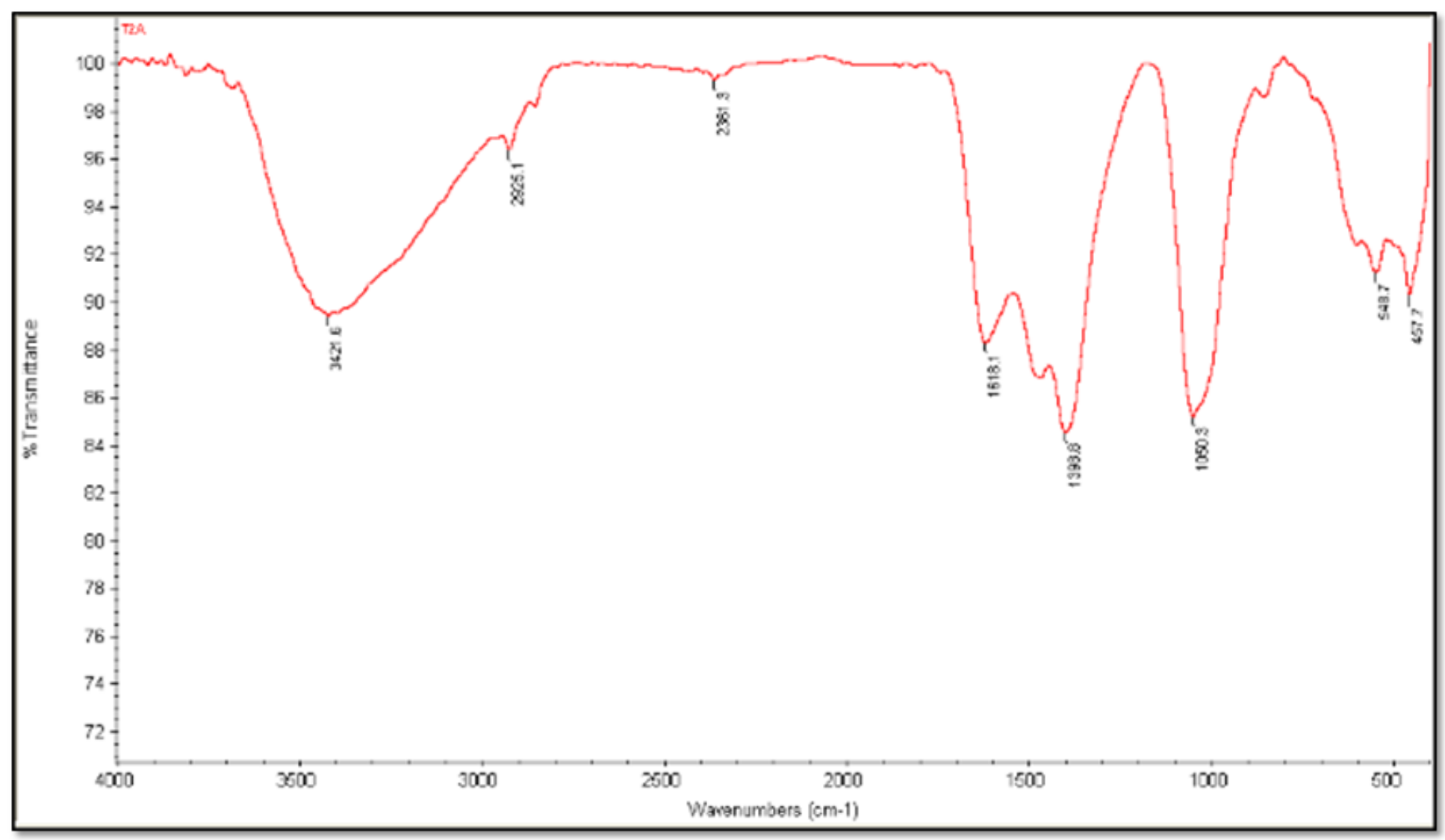

Figure 13

FTIR Spectrum of Copper nanoparticles. 


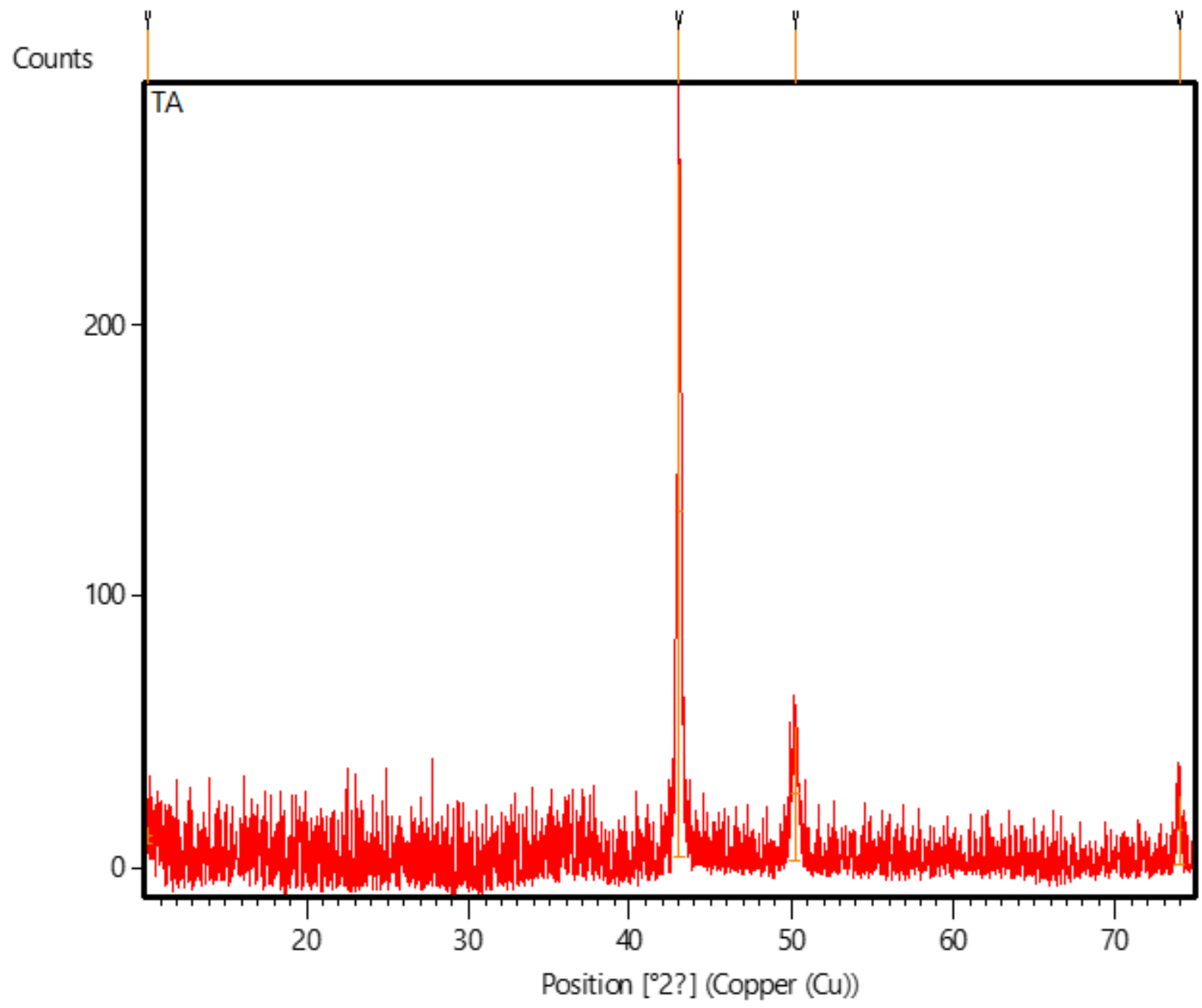

Figure 14

The X-Ray diffraction pattern of the copper nanoparticles. 


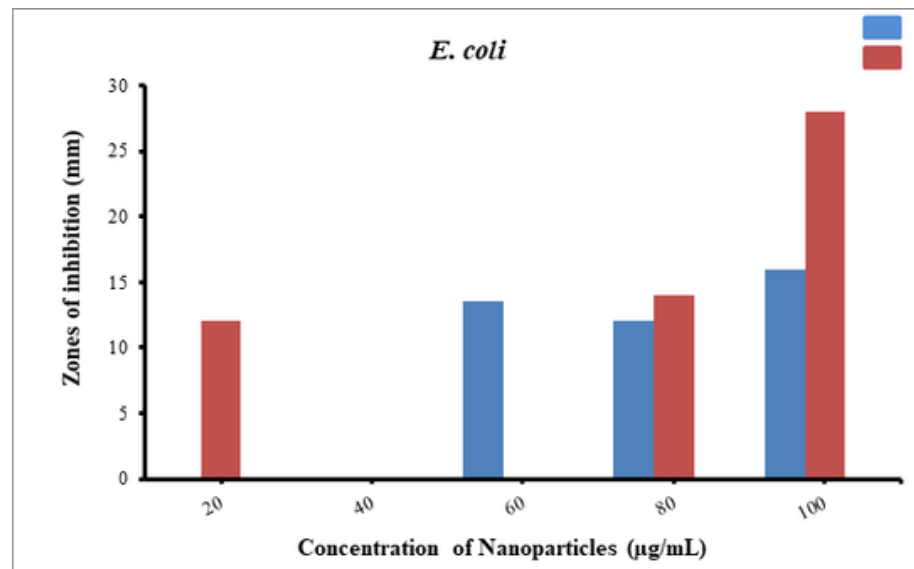

a

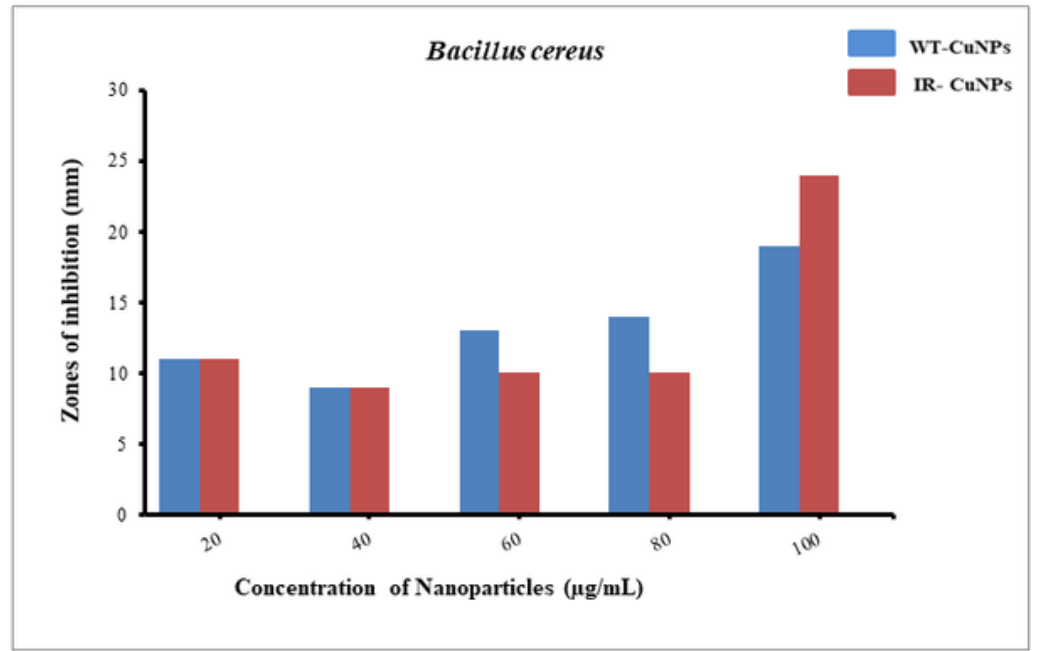

b

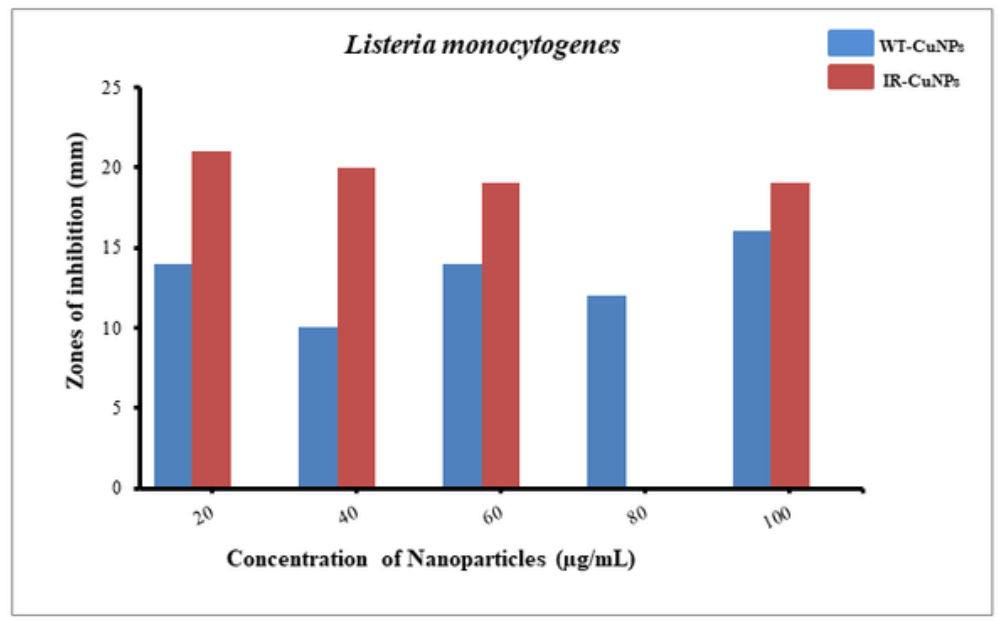

c

Figure 15

Graphical presentation of the effect of copper nanoparticles synthesized from wild type and irradiated strains of A. occultus MN259598 on food borne bacterial pathogens (a) Escherichia coli (b) Bacillus cereus (c) Listeria monocytogenes. In all three scenarios, the particles synthesized from irradiated samples showed maximum inhibition compared to the wild type. 
Page 33/33 